\title{
GAS Y ELECTRICIDAD: ¿QUÉ HACER AHORA?*
}

\author{
Alexander Galetovic, Juan Ricardo Inostroza \\ y Cristián Marcelo Muñoz
}

La traída del gas natural argentino para generar energía eléctrica fue muy beneficiosa para Chile. Si se pierde el gas argentino - advierten los autores de este trabajo-, el costo de generación de electricidad, sólo en el SIC, aumentará en aproximadamente US\$ 350 millones por año. Esta pérdida es grande: equivale a $0,5 \%$ del PGB o a la mitad del valor de los acuerdos comerciales que Chile firmó con los Estados Unidos y la Unión Europea.

¿Por qué en Chile central una escasez de agua o de gas natural deviene en una crisis eléctrica? En este estudio se sostiene que la disponibilidad volátil de agua y de gas natural, por sequía o por corte, obligan a reducir el consumo en años de escasez extrema. Sin

Alexander Galetovic. Profesor del Centro de Economía Aplicada (CEA), Departamento de Ingeniería Industrial, Universidad de Chile.

JuAn Ricardo Inostroza. Gerente de Regulación y Desarrollo de AES Gener S.A.

Cristí́n Marcelo Muñoz. Jefe de Departamento Regulación y Desarrollo.

* Este trabajo fue financiado por AES Gener S. A. Su contenido, sin embargo, es de exclusiva responsabilidad de sus autores y no compromete de manera alguna a AES Gener S. A. Los autores agradecen los comentarios de Renato Agurto, Ricardo Paredes, Salvador Valdés y de los participantes en los seminarios del Banco Central, CEA-Decon, Centro de Estudios Públicos, Encuentro de la Sociedad de Economía, Ilades, Instituto Libertad, Instituto Libertad y Desarrollo, Jornadas de Derecho Eléctrico y Universidad Católica de Chile. Alexander Galetovic también agradece el financiamiento de la Fundación Hewlett, a través de un grant institucional al CEA. 
embargo, las situaciones de escasez no necesariamente deben terminar en crisis. Éstas ocurren — plantean los autores_ porque el sistema de precios es inflexible.

Para solucionar el problema se propone eliminar el límite de clientes libres, separar la comercialización de energía de su distribución y liberalizar los precios y las condiciones de contrato. Esta liberalización, se señala, permitiría seguir usando gas natural argentino sin que los cortes de suministro generen crisis de abastecimiento. Además, la liberalización no tendría por qué aumentar los precios sino que, por el contrario, la competencia debería provocar caídas de tarifas que en buena parte compensarían los costos de una hipotética pérdida completa del gas natural argentino.

\section{Introducción y motivación}

$\mathrm{N}$ o bien se aprobó la latamente discutida ley corta, la crisis del gas natural amenazó con el desabastecimiento eléctrico. Desde que ocurrieron los cortes la discusión se centró en cómo asegurar abastecimiento confiable de combustibles; incluso, algunos proponen abandonar el gas natural. Este trabajo adopta una perspectiva distinta y se pregunta qué condiciones son necesarias para que una escasez de gas natural no amenace al abastecimiento de corto y de largo plazo.

La conclusión del trabajo es que significaría un error muy costoso abandonar el gas natural argentino: de hecho, en la sección 2 mostramos que el costo sería similar a perder el tratado de libre comercio con Estados Unidos o el tratado con la Unión Europea. Al mismo tiempo, argumentamos que para salvar al gas argentino es necesario modificar el sistema de precios de la electricidad para adaptarlo a la condición habitual de este mercado: la disponibilidad de insumos para generar electricidad, tales como el agua y el gas natural, es volátil y varía año a año. Para ello proponemos eliminar el precio de nudo y, con una sola excepción, liberalizar las condiciones de contrato entre usuarios y comercializadores de energía.

El punto de partida de nuestro análisis es distinguir entre combustibles de disponibilidad volátil y combustibles de disponibilidad segura. El agua y - hemos aprendido este año- el gas natural son combustibles de disponibilidad volátil: vale decir, la cantidad disponible año a año es incierta. A diferencia del agua y del gas, la disponibilidad de petróleo y de carbón no es volátil, porque si ocurre un shock petrolero o aumenta el precio del carbón, se podría continuar consumiendo la misma cantidad, 
aunque sería más caro. El punto es que el petróleo y el carbón son commodities cuyo mercado es profundo y se pueden comprar cantidades que para todos los efectos prácticos son ilimitadas, si se está dispuesto a pagar el precio (por supuesto, en la práctica la demanda no es perfectamente inelástica y la cantidad demandada cae cuando aumenta el precio). Por contraste, cuando se trata de agua o de gas natural, el consumo tiene que caer cuando ocurre escasez, por la simple razón de que la restricción es física. El defecto del actual sistema de precios de electricidad, y la explicación de que una escasez de agua o de gas natural puede devenir en crisis, es que no tiene la suficiente flexibilidad para acomodar las disponibilidades volátiles de combustibles, se trate de agua, de gas o, quizás en el futuro, del viento o la geotermia.

A primera vista podría parecer curioso afirmar que la escasez de gas natural no amenazaría el abastecimiento si el sistema de precios para los usuarios finales fuera distinto. Después de todo, es un hecho que si no llega gas hay menos con qué generar y eso debiera causar problemas, por lo menos en el corto y mediano plazo. Pero si se examina con un poco más de cuidado, la creencia de que una escasez de gas debe devenir en crisis parte de la premisa de que el consumo de electricidad es fijo ${ }^{1}$. Eso supone, sin embargo, que el precio es fijo y no responde a las condiciones de oferta. Si el costo de consumir energía aumentase lo suficiente en el margen cuando ocurre una escasez, ésta no se transformaría en crisis porque el consumo se ajustaría a la menor disponibilidad de energía. Por supuesto, se suele creer que la demanda por electricidad es completamente insensible al precio. Pero tal creencia es contradicha por la evidencia internacional y, recientemente, por el estudio de Benavente et al. (2004) sobre la demanda por electricidad residencial en Chile. Estos estudios indican que la elasticidad de la demanda residencial es grande, económicamente hablando, tanto en el corto como en el largo plazo. Esto permite, en principio, manejar una escasez mediante los precios.

¿Por qué es rígido el sistema de precios vigente? Para comenzar, por razones bien conocidas, los usuarios no ven que el costo de oportunidad de la energía aumenta cuando los argentinos cortan el gas o hay una sequía $^{2}$. Segundo, esta rigidez de corto plazo, que se torna importante una vez que la escasez se materializa, se combina con una rigidez de largo plazo: el seudocontrato impuesto por el precio de nudo impone una sola calidad de servicio e impide que las preferencias y disposiciones a pagar de

${ }^{1}$ Por escasez entendemos una caída de la oferta de energía, ya sea porque se interrumpe el suministro de gas, ocurre una sequía o falla una central. Por crisis entendemos un exceso de demanda por energía, el que habitualmente obliga a disponer cortes del suministro.

${ }^{2}$ Véase a Díaz et al. (2000) o Fischer y Galetovic (2003). 
los usuarios por niveles alternativos de seguridad se reflejen en contratos y precios diferenciados.

¿Cómo deben corregirse estos defectos? Proponemos eliminar el precio de nudo y sustituirlo por contratos libres entre comercializadores y usuarios. Para hacerlo, sin embargo, es necesario separar la distribución de electricidad -el servicio que prestan los cables que la conducen hasta los consumidores - de su comercialización.

A primera vista podría parecer extraño que sea necesario modificar la estructura del mercado eléctrico para acomodarse a insumos de disponibilidad volátil. Pero las razones son fundamentales y se deben a lo siguiente: una vez que ocurre una escasez, hay consumidores cuyo costo de disminuir su consumo es menor que para otros. Una administración eficiente de la escasez se logra cuando se deja de consumir los KWh que valen menos, y para eso se necesitan agentes con incentivos para encontrarlos; es decir, agentes que ganen dinero detectando a quienes pueden disminuir su consumo a bajo costo. En un mercado común y corriente, donde todas las transacciones se hacen al precio spot, el mecanismo es muy simple y directo: el precio sube hasta que se igualan oferta y demanda. En el mercado eléctrico es algo más complicado, porque generalmente los clientes contratan a precios estabilizados que suavizan las variaciones del precio spot y no reflejan la escasez relativa de energía en cada momento. Por lo tanto, se requiere algo más que un simple aumento de precios para detectar a los consumidores que están dispuestos a disminuir su consumo al menor costo.

Al mismo tiempo, algunos consumidores valoran más que otros quedar cubiertos contra una escasez. Por ejemplo, seguramente un laboratorio prefiere contratar suministro a todo evento; un contrato como ése debiera estar respaldado por una central de carbón. Pero muchos de nosotros estamos dispuestos a bajar ocasionalmente la potencia de las ampolletas o apagar las estufas eléctricas que usamos en la casa si se nos hace una oferta suficientemente atractiva; por eso, estaremos dispuestos a tomar un contrato respaldado por una central de gas o de agua. Las distintas disposiciones a pagar por abastecimiento seguro debieran reflejarse en los contratos y en los precios, y finalmente determinar la composición del parque de generación ${ }^{3}$.

Con distribuidoras que monopolizan la comercialización dentro de sus zonas de concesión, tal liberalización de precios y condiciones de contrato es impensable, porque las dejaría libres para explotar su poder de

${ }^{3}$ Por supuesto, ambas decisiones están ligadas. Seguramente, quienes anticipen costos pequeños de disminuir consumo, una vez que se materializa una escasez, serán quienes tomen contratos que los obliguen ocasionalmente a disminuir su consumo. 
mercado. Al final, terminaríamos con un regulador visando contratos o, peor aún, diseñándolos y poniéndoles precio — precisamente lo que causa el problema que estamos tratando de resolver-. Por contraste, argumentaremos que la comercialización de energía no debería estar sujeta a economías de escala importantes y, por lo tanto, se puede confiar en que será competitiva.

Una objeción (o más bien temor) a la liberalización es que los precios aumenten. En la sección 5 mostraremos dos razones de por qué la competencia debiera reducir los precios que paga la señora Juanita, una vez que éstos se liberalicen ${ }^{4}$. En primer lugar, actualmente el precio de la energía residencial incluye el pago de la potencia y parte de las instalaciones de distribución. Esto distorsiona la decisión marginal de cuánta energía demandar; estimamos que si esta distorsión se elimina (como debiera ocurrir en competencia), el aumento de bienestar de los consumidores sería equivalente a bajarles el precio en alrededor de $8 \%$. Además, los cambios de tarificación que traería la liberalización seguramente incentivarían desplazar consumo desde las horas punta hacia las horas valle, y con ello el costo de abastecimiento sería menor. Mostramos que la sola suma de estos dos beneficios de la competencia bastaría para compensar una buena parte de la pérdida completa del gas natural argentino.

La liberalización de la comercialización también evitaría que la escasez de agua o gas devenga en crisis y con ello disminuiría su costo. ¿Cuánto? Actualmente las reducciones de consumo se logran, en principio, con reducciones parejas de consumo. Las estimaciones más recientes del costo de falla indican que cada KWh restringido de esta forma causa una pérdida de alrededor de US $\$ 0,22 / \mathrm{KWh}$. Lo eficiente, sin embargo, es que se dejen de consumir aquellos KWh que valen marginalmente menos. Si así ocurriera, estimamos que el costo de una escasez debiera ser alrededor de US\$ $0,05 / \mathrm{KWh}$, es decir, menos de un cuarto del costo actual. Argumentaremos que los comercializadores tendrán incentivos para encontrar a quienes les cuesta menos disminuir su consumo en el margen.

Antes de seguir, vale la pena advertir que algunos de nuestros cálculos son aproximados. Por ejemplo, utilizaremos repetidamente una estimación de la elasticidad de la demanda residencial de Benavente et al. (2004) para calcular los beneficios de medidas determinadas, las cuales, por brevedad, no reportaremos aquí y se entiende que el estimador de tal coeficiente tiene asociada una desviación estándar. Sin embargo, creemos que

${ }^{4}$ La señora Juanita es un personaje inventado por el Presidente Ricardo Lagos, y que representa al consumidor medio chileno. En adelante nos referiremos repetidamente a la señora Juanita. Si bien coloquial, la expresión es apreciablemente más precisa que términos tales como consumidor representativo. 
los órdenes de magnitud que tales números arrojan son apropiados y en lo que sigue los utilizaremos sin reiterar las excusas.

El resto del trabajo se organiza como sigue. En la sección 2 comenzamos aclarando una serie de afirmaciones que han circulado durante esta crisis. Varias son falacias que conviene refutar, porque confunden la discusión. En la sección 3 diagnosticamos por qué el sistema de precios vigente es inadecuado. En la sección 4 exponemos nuestra propuesta. En la sección 5 presentamos una serie de cálculos para fundamentar nuestra afirmación de que la electricidad no debería aumentar de precio si se liberaliza la comercialización. La sección 6 concluye. En un apéndice explicamos en qué consiste el sistema actual de administración de déficit y precisamos algunos de nuestros cálculos.

\section{2. ¿Qué está en juego?}

Antes de proponer soluciones es conveniente hacerse cargo de varias afirmaciones que han coloreado el debate, confundiéndolo.

¿Cuánto perderíamos por no tener más gas natural? Se han propuesto varios sustitutos para el gas — - v. gr., carbón, gas licuado y hasta geotermia o viento-, pero rara vez se ha dicho cuánto costarían. El hecho es que cualquier alternativa es considerablemente más cara. Por eso es conveniente comenzar con una estimación del costo que significaría para el país perder el gas natural.

En todo momento existe en el sistema eléctrico una tecnología de expansión. Se trata del tipo de central económicamente más conveniente entre aquellas cuya tecnología y combustible están libremente disponibles en el mercado. Este tipo de central siempre se puede usar para aumentar la capacidad del sistema cada vez que sea necesario. Esto no quiere decir que sólo se construirán centrales de ese tipo. Ocasionalmente habrá proyectos más baratos, pero sin réplicas libremente disponibles en el mercado. Por ejemplo, en Chile se hacen proyectos hidráulicos, pero por razones que discutiremos más adelante sería muy caro expandir el sistema sólo con este tipo de centrales.

La tecnología de expansión determina el precio de largo plazo de la electricidad. Grosso modo, en el largo plazo el precio monómico promedio de la electricidad debe ser suficientemente alto para que las inversiones en la tecnología de expansión obtengan una rentabilidad normal acorde con el 
riesgo del negocio de generación ${ }^{5,6}$. El Cuadro $\mathrm{N}^{\circ} 1$ muestra el precio monómico a nivel de generación que es necesario para rentar las distintas alternativas tecnológicas.

Hasta la crisis del gas, la tecnología de expansión eran los ciclos combinados. Una central de gas era la alternativa más conveniente, porque se pensaba que el gas natural estaría libremente disponible. El promedio del precio de nudo entre 2000 y 2003 es una estimación razonable (e independiente) del precio de largo plazo de la energía en esas circunstancias: US\$ 34,7/MWh ${ }^{7}$.

Considérese ahora qué ocurriría de no llegar más gas natural. Las alternativas para sustituirlo son centrales de carbón o de gas licuado (por el momento, el viento y la geotermia se pueden descartar porque son tecnologías apreciablemente más caras). La columna 2 del Cuadro $\mathrm{N}^{\circ} 1$ muestra que, comparado con el gas, el costo de expandir el sistema con carbón es US\$ 11,7/MWh más caro (US\$ 46,4/MWh contra US\$ 34,7/MWh). ¿Qué tan grande es esta magnitud? El consumo anual en el Sistema Interconectado Central (SIC) es alrededor de $30.000 \mathrm{GWh}$ al año. Si se multiplica por los US\$ 11,7/MWh de diferencia se llega a los US\$ 352,5 millones anuales que se muestran en la columna 3 ; algo así como $0,5 \%$ del $\mathrm{PGB}^{8}$. La columna 4 estima el valor presente del mayor costo suponiendo que el consumo crece 5\% cada año y la tasa de descuento es $10 \%$ real, ambos supuestos conservadores que subestiman la magnitud de la pérdida. El mayor costo es de US\$ 7.050 millones en valor presente. Finalmente, la columna 5 indica que el mayor costo es equivalente al $13 \%$ del precio de la energía a nivel de cliente final.

El Cuadro $\mathrm{N}^{\circ} 1$ también sugiere que el gas licuado es una alternativa inconveniente como tecnología de expansión del sistema eléctrico. Si

${ }^{5}$ La potencia es la capacidad de desarrollar trabajo mecánico, y se mide en watts (W). La energía es el uso o generación de potencia en un período de tiempo y se mide en watts por hora o watts-hora (Wh). Así, por ejemplo, una ampolleta de $100 \mathrm{~W}$ de potencia consume $50 \mathrm{Wh}$ de energía si está encendida por media hora. Un kilowatt (KW) son 1000 watts; un megawatt (MW) son $1.000 \mathrm{KW}$ y un gigawatt $(\mathrm{GW})$ son $1.000 \mathrm{MW}$.

${ }^{6} \mathrm{El}$ precio monómico de la energía indica el costo promedio de un KWh habida consideración del pago de potencia que se debe hacer. Es decir, es igual a

$$
\frac{p_{e} \cdot e+p_{p} \cdot p}{e},
$$

donde $p_{e}$ es el precio de la energía, $p_{p}$ el de la potencia, $e$ la cantidad total de energía consumida y $p$ la cantidad de potencia utilizada durante la hora del año cuando el consumo es máximo.

${ }^{7}$ En la sección 3 explicamos cómo se calcula el precio de nudo.

${ }^{8}$ La pérdida, por supuesto, es mayor: el gas natural también se ocupa para generar electricidad en el norte de Chile y se consume directamente en Chile central y en la zona de Concepción. 
CUADRO N$^{\circ}$ 1: $\quad$ COSTOS DE LARGO PLAZO DE LA ELECTRICIDAD CON DISTINTAS

ALTERNATIVAS TECNOLÓGICAS

\begin{tabular}{|c|c|c|c|c|}
\hline (1) & (2) & (3) & (4) & (5) \\
\hline $\begin{array}{l}\text { Inversión } \\
\text { (dólares } \\
\text { por } \mathrm{KW})^{\mathrm{i}}\end{array}$ & $\begin{array}{c}\text { Costo de } \\
\text { la energía } \\
\text { (dólares por } \\
\text { MWh) }\end{array}$ & $\begin{array}{l}\text { Mayor costo } \\
\text { por año } \\
\text { (millones de } \\
\text { dólares) }\end{array}$ & $\begin{array}{l}\text { Mayor costo } \\
\text { de largo plazo } \\
\text { (millones de } \\
\text { dólares) }\end{array}$ & $\begin{array}{c}\text { Mayor costo } \\
\text { de largo plazo } \\
\text { (\% por }^{\text {KWh final })^{\text {iv }}}\end{array}$ \\
\hline
\end{tabular}

Precio de nudo 2000-03

(Ciclo combinado, gas natural, sin restricción $)^{\mathrm{a}}$

Ciclo combinado, gas natural, restringido 500 horas por año ${ }^{b}$

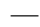

506

Carbón $^{\mathrm{c}}$

1.294

Ciclo combinado, gas licuado ${ }^{\mathrm{d}}$
41,7

46,4

210,9

4.218

$8 \%$

352,5

7.050

$13 \%$

$50,0 \quad 459,3$

$17 \%$

Notas: En cada caso se supone que el precio de largo plazo de la electricidad se ajusta para rentar, a la tecnología de expansión.

\section{Columnas:}

La columna (1) indica el costo de inversión en dólares por KW de potencia instalada de cada alternativa, a la tasa de descuento que exigen los inversionistas.

La columna (2) indica el precio monómico (es decir, aquel que combina energía y potencia) necesario para que la planta obtenga el retorno exigido por los inversionistas. El factor de carga se supuso igual a 74,4\%, que es el factor de carga del sistema según el informe de precio de nudo de la CNE de abril de 2004.

La columna (3) muestra en cada caso el valor presente del mayor costo de abastecimiento relativo a la situación en que el gas natural llega al precio vigente hoy sin interrupciones de ninguna especie. Para obtenerlo se supuso que el consumo del SIC hoy es de 30.000 GWh; crece 5\% cada año y se descontaron los flujos al $10 \%$.

La columna (4) muestra el mayor costo de la alternativa respectiva como porcentaje del costo de un $\mathrm{KWh}$ valorado a precio de consumidor final. El precio final de referencia es $\$ 54,5 / \mathrm{KWh}$, o sea, la tarifa BT1 promedio de Chilectra en abril de 2004. En dólares equivale a US\$ 90,9/MWh al tipo de cambio de $\$ 600$ por dólar. La tarifa BT1 incluye generación (energía y potencia), transmisión y distribución.

\section{Lineas:}

a La alternativa "sin restricción" corresponde al promedio actualizado a marzo 2004 de los precios de nudo monómicos desde abril de 2000 hasta octubre de 2003. Esta alternativa es una indicación razonable del costo de abastecimiento de largo plazo si la expansión del sistema ocurre mayormente con centrales de gas natural sin restricción. La fuente es la CNE.

${ }^{\mathrm{b}} \mathrm{La}$ "restricción 500 horas" significa que el gas natural no llega durante 500 horas cada año y que se reemplaza quemando petróleo diésel. El precio del gas supuesto es US\$ 86,5 por $\mathrm{dm}^{3}$ (incluye transporte según contrato take-or-pay). Se supone que los ciclos combinados se instalan en la VI Región. Por el mayor riesgo, se supone que los inversionistas exigen un retorno de $11,5 \%$ real.

${ }^{\mathrm{c}} \mathrm{Se}$ supuso que el precio del carbón sería igual al promedio registrado en la central Ventanas en los últimos cinco años. El costo de inversión supone que la central se ubica en la V Región y que los inversionistas exigen un retorno de $10 \%$ real.

${ }^{d}$ Se supone que el precio final del gas licuado es US\$ 173 por $\mathrm{dm}^{3}$ e incluye la inversión para construir una planta que licua el gas, los barcos para traerlo a Chile y el costo de los gasoductos para conectarse a los gasoductos existentes. Se supone que los inversionistas exigen una tasa de retorno igual a $10 \%$ real. 
éste creciera con gas licuado, el costo de la electricidad aumentaría a US\$ 50/MWh. El gas licuado cuesta US\$ 459,3 millones más por año que el gas natural, US\$ 9.186 millones más en valor presente, o el equivalente al $17 \%$ del precio de la energía a nivel de cliente final. En resumen:

Hecho 1. Si el gas se pierde, el costo de abastecimiento eléctrico será considerablemente mayor: US\$ 352,5 millones anuales en el SIC, US\$ 7.050 millones en valor presente y $13 \%$ más a nivel de la cuenta de un usuario final residencial.

¿Qué tan grande es una pérdida de US\$ 352,5 millones? Para calibrar su magnitud es revelador compararlo con la ganancia que obtuvo el país por firmar los recientes acuerdos de libre comercio. En un estudio reciente, Chumacero et al. (2004) cuantificaron cuidadosamente estas ganancias, y concluyeron que los acuerdos con la Unión Europea y los Estados Unidos sumados aumentarán permanentemente el nivel del PGB chileno en alrededor de $1 \%$. En otras palabras, iperder el gas natural anularía la mitad de las ganancias logradas al firmar estos dos acuerdos!

Es evidente que estos números sobrestiman en algo la bondad del gas natural, porque el precio de nudo se calculaba suponiendo que estaría libremente disponible, lo que, sabemos ahora, no es cierto. Sin embargo, bastan para mostrar que es extremadamente rentable encontrar un mecanismo que permita seguir usándolo a pesar de que se interrumpa de vez en cuando. No deja de llamar la atención que el gobierno, habiendo invertido varios años y grandes esfuerzos para negociar cada acuerdo de libre comercio, no esté dispuesto a invertir prácticamente nada para diseñar una solución que permita que el gas natural argentino continúe siendo la tecnología de expansión del sistema eléctrico.

¿Fue mal negocio traer el gas? Se ha criticado mucho la decisión de traer el gas y algunos hasta afirman que el costo de abastecimiento eléctrico terminará siendo mayor. Pero unos segundos de reflexión bastan para darse cuenta de que tal afirmación es absurda. En el peor de los casos - es decir, si se abandona el gas natural-, el sistema eléctrico continuaría creciendo con centrales de agua y carbón, exactamente igual que antes de la llegada del gas. Por lo tanto, el precio sería igual a que si nunca hubiera llegado el gas, con la diferencia de que entre 1995 y 2003 se generó electricidad a un costo considerablemente menor. ¿Cuánto menos? 
GRÁFICO N 1: $\quad$ PRECIO DE NUDO MONÓMICO, 1987-2003 (EN DÓLARES POR MWH)

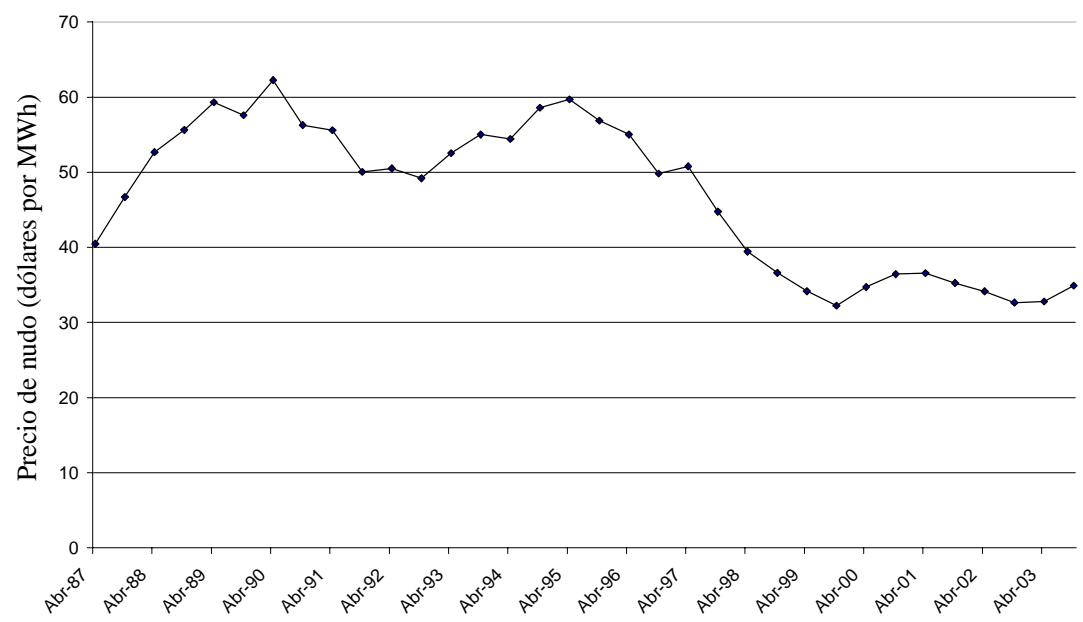

Año

El Gráfico $\mathrm{N}^{\circ} 1$ muestra el precio de nudo monómico entre 1987 y 2003. Nótese que hasta 1996 el precio se mueve entre US\$ 50/MWh y US\$ 60/MWh. Con la llegada del gas, y a partir de 1997, el precio cae violentamente y se estabiliza entre US\$ 30/MWh y US\$ 40/MWh. En promedio, el precio cae 33,5\%, desde US\$ 53,77/MWh (promedio entre abril de 1987 y abril de 1997) a US\$ 35,75/MWh (promedio entre octubre de 1997 y octubre de 2003). Vale decir, el precio de la electricidad a nivel de generación cayó alrededor de un tercio ${ }^{9}$. ¿Cuánto suman los beneficios del gas natural desde 1998? Una estimación rápida del orden de magnitud se obtiene del Cuadro 1. Si desde 1998 hasta 2003 valoramos la producción de cada año al precio monómico del gas y del carbón, se obtiene que la diferencia es algo más de US\$ 2.000 millones $^{10}$.

${ }^{9}$ Al lector informado podría sorprenderle que la caída del precio comienza antes de que entren las primeras centrales de gas a principios de 1998. Esta caída ocurrió porque la llegada futura del gas cambió el plan de obras y adelantó el uso del agua del lago Laja y del resto de los embalses. Cabe señalar que los primeros ciclos combinados empezaron a ser considerados en los planes de obras de la Comisión Nacional de Energía recién en 1995.

${ }^{10}$ La producción de cada año es: 1998: $25.650 \mathrm{GWh}$; 1999: $26.915 \mathrm{GWh}$; 2000: 29.577 GWh; 2001: 30.765 GWh; 2002: 31.971 GWh; 2003: 33.708 GWh. Para obtener el cálculo, estas cantidades se multiplicaron por $(46,4 \mathrm{US} \$ / \mathrm{MWh}-34,7 \mathrm{US} \$ / \mathrm{MWh})=11,7$ US\$ MWh, que es la diferencia entre el costo de abastecimiento con gas y carbón que se obtiene del Cuadro $\mathrm{N}^{\circ} 1$. El total es US\$2.089,5 millones. 
Hecho 2. La traída del gas hizo caer el precio de la electricidad a nivel de generación en alrededor de un tercio y entre 1998 y 2003 disminuyó el costo de abastecimiento en más de US\$2.000 millones.

\section{El agua: ¿una fuente de abastecimiento más segura pero posterga-} da? Una crítica recurrente a la regulación eléctrica es que ha perjudicado a la generación hidráulica. Se pueden tener opiniones diversas sobre qué significa exactamente perjudicar a la generación hidráulica, pero es conveniente echarle una mirada a la evolución de su participación en la capacidad instalada y en la producción de energía.

El Cuadro $\mathrm{N}^{\circ} 2$ muestra la participación de los distintos tipos de centrales en la capacidad total instalada en el SIC en 2003. De los 6.990 MW de capacidad que estaban instalados en 2003, el 58\% correspondía a centrales hidráulicas y sólo el $25 \%$ a ciclos combinados a gas natural. El Gráfico $\mathrm{N}^{\circ} 2$ muestra la participación de la energía hidráulica en el total de la energía generada entre 1985 y 2003. Desde la llegada del gas, y salvo en años muy secos, alrededor del $65 \%$ de la generación de energía eléctrica se hace con agua. Por eso, si bien la participación del agua disminuyó después de la llegada del gas, sigue siendo mayoritaria.

\section{CUADRO N $^{\circ}$ 2: $\quad$ CAPACIDAD INSTALADA EN EL SIC EN 2003}

(1)

Tipo de central
(2)

Capacidad instalada $(\text { en MW })^{\mathrm{i}}$
(3)

Participación

\begin{tabular}{lrc}
\hline Pasada & 1.295 & $19 \%$ \\
Embalse & 2.754 & $39 \%$ \\
Total hidráulico & $\mathbf{4 . 0 4 9}$ & $\mathbf{5 8 \%}$ \\
Carbón & 838 & $12 \%$ \\
Gas natural & 1.717 & $25 \%$ \\
Petróleo y derivados & 307 & $4 \%$ \\
Otros & 79 & $1 \%$ \\
Total térmico & 79 & $\mathbf{4 2 \%}$ \\
Capacidad instalada & $\mathbf{2 . 9 4 1}$ & $\mathbf{1 0 0 \%}$ \\
Demanda máxima (2003) & $\mathbf{6 . 9 9 0}$ & \\
\hline
\end{tabular}

Notas (i) La capacidad instalada es igual a la potencia instalada. (ii) La categoría "otros" incluye centrales de vapor, de licor negro y aquellas que queman desechos forestales.

Fuente: Estadístico CDEC-SIC (2003). 
GRÁFICO N ${ }^{\circ}$ 2: $\quad$ PARTICIPACIÓN DE LA ENERGÍA HIDRÁULICA EN LA GENERACIÓN TOTAL, 1985-2003

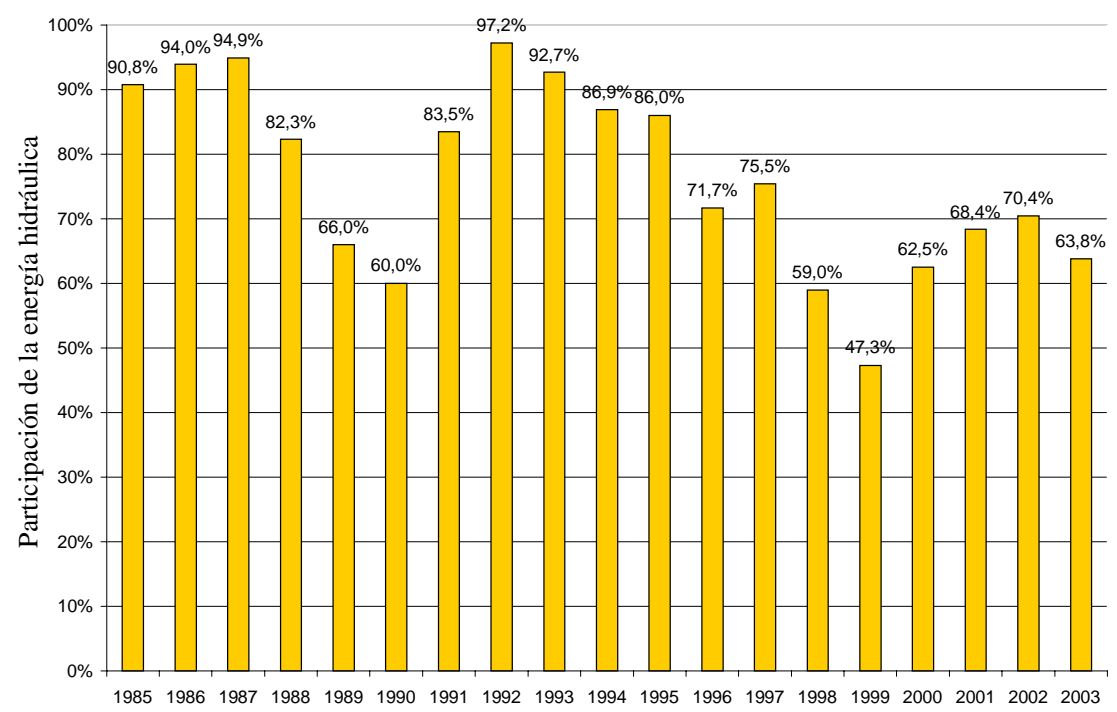

Hecho 3. La generación hidráulica es mayoritaria en Chile.

Que la energía hidráulica sea mayoritaria implica que el SIC está sujeto a un importante riesgo hidrológico, porque gran parte de la energía se genera en plantas hidroeléctricas que, con la excepción del lago Laja, no tienen capacidad de embalse interanual y dependen de los caudales de cada año ${ }^{11}$. En otras palabras, el agua es un combustible cuya disponibilidad es volátil.

El Gráfico $\mathrm{N}^{\circ} 3$ muestra la cantidad de energía hidráulica que se podría haber generado en el SIC con el actual parque de centrales hidráulicas (con Ralco) en cada uno de los años hidrológicos entre 1962-1963 y 2001-2002 $2^{12}$. Considerando que la producción anual en el SIC en 2003 fue $33.708 \mathrm{GWh}$, se puede apreciar que en un año muy húmedo, tal como

${ }^{11}$ Un embalse es de regulación interanual si se necesita más de un año para generar su contenido cuando está lleno.

${ }^{12}$ El ejercicio supone que los embalses parten y terminan el año hidrológico en el mismo nivel, vale decir, las centrales generan todo el flujo de agua que reciben durante el año hidrológico. 


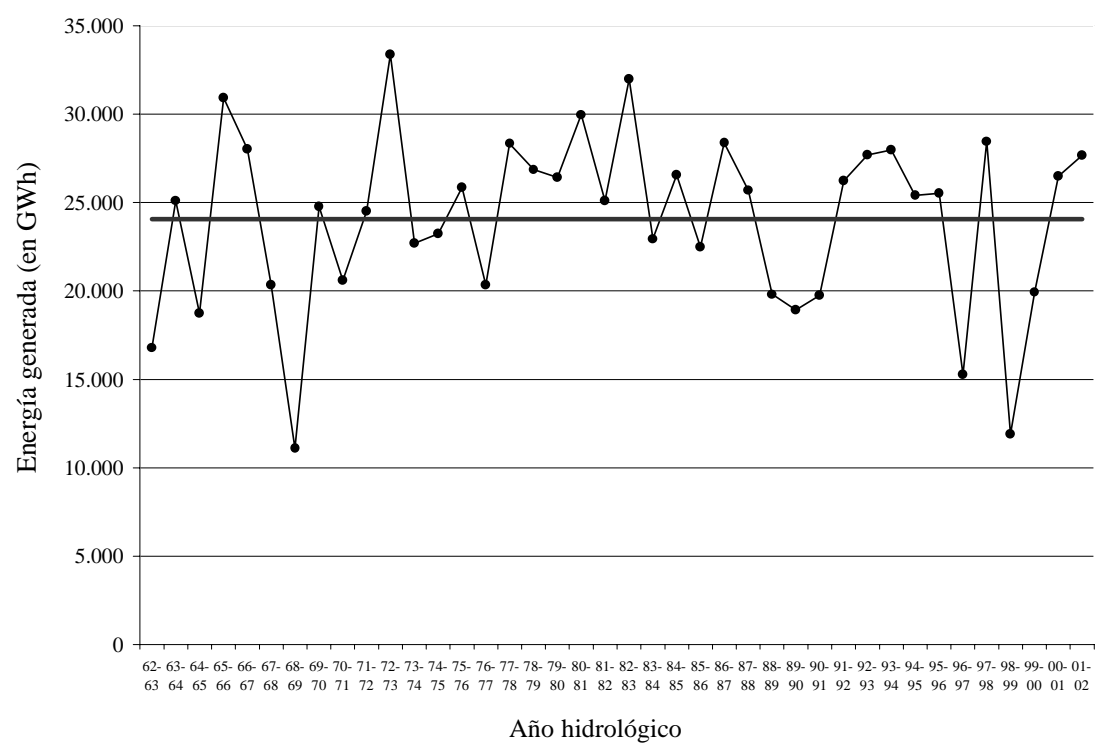

1972-1973, más del 100\% del consumo se puede abastecer con generación hidráulica. En un año de hidrología promedio, la generación hidráulica permite abastecer poco más del $70 \%$ del consumo (poco más de 24.000 GWh), mientras que en un año muy seco, como 1968-69 ó 1998-99, apenas algo más que de $11.000 \mathrm{GWh}$, o cerca de un tercio de la cantidad demandada es abastecida con generación hidráulica. Vale decir, en un año muy seco desaparecen alrededor de $13.000 \mathrm{GWh}$, más de la mitad de la energía hidráulica disponible normalmente, equivalente a más o menos un tercio de la producción anual ${ }^{13}$. Esto implica que el agua no es una fuente de abastecimiento segura, si por ello se entiende que su disponibilidad es constante o a lo menos predecible año a año. Es más, es interesante notar que toda la producción anual en plantas de gas natural no sobrepasa los $9.000 \mathrm{GWh}$. Vale decir, eventos tales como la crisis del gas argentino de este año, que significaron cortes parciales del suministro de gas natural, son sobrepasados con holgura por el riesgo de sequía extrema con que siempre vive el SIC.

${ }^{13}$ ¿Cuán severa y prolongada puede ser una sequía? El Gráfico $\mathrm{N}^{\circ} 2$ da una buena idea si nos limitamos al período en que existen estadísticas sistemáticas, las que comenzaron con el año hidrológico 1940-41. Sin embargo, el trabajo de Enrique Taulis (1934) indica que en el siglo 18 se sucedieron 13 años secos entre 1770 y 1782 . 
Hecho 4. El agua no es una fuente de abastecimiento "segura" porque la variabilidad hidrológica es apreciable. Por lo tanto, su disponibilidad es volátil.

Hay una manera distinta y complementaria de mostrar que el agua no es segura, y por esa razón no puede ser la tecnología de expansión. El Cuadro $\mathrm{N}^{\circ} 3$ muestra la capacidad adicional que sería necesaria a partir de 2005 para garantizar que no haya racionamiento, a menos que ocurra una sequía peor que la del año hidrológico 1998-99. La columna 3 muestra la

CUADRO N ${ }^{\circ}$ 3: $\quad$ EL AGUA NO ES LA TECNOLOGÍA DE EXPANSIÓN

\begin{tabular}{lccccccc}
\hline & $\begin{array}{c}(1) \\
\text { Demanda } \\
(\text { en GWh) }\end{array}$ & $\begin{array}{c}\text { Aumento } \\
\text { de la } \\
\text { demanda } \\
(\text { en GWh) }\end{array}$ & $\begin{array}{c}\text { Inversión } \\
\text { hidráulica } \\
\text { (adicional, } \\
\text { en MW) }\end{array}$ & $\begin{array}{c}\text { (4) } \\
\text { Inversión } \\
\text { carbón } \\
\text { (adicional, } \\
\text { en MW) }\end{array}$ & $\begin{array}{c}\text { (5) } \\
\text { Costo } \\
\text { anual } \\
(\text { en US\$ } \\
\text { millones) }\end{array}$ & $\begin{array}{c}\text { (6) } \\
\text { Costo } \\
\text { anual } \\
\text { (en US\$ } \\
\text { millones) }\end{array}$ & $\begin{array}{c}\text { (7) } \\
\text { Diferencia } \\
\text { (en US\$ } \\
\text { millones) }\end{array}$ \\
\hline 2005 & 38.592 & 2.525 & 770 & 360 & 234 & 138 & 96 \\
2006 & 41.294 & 2.701 & 824 & 385 & 250 & 148 & 102 \\
2007 & 44.184 & 2.891 & 882 & 412 & 267 & 158 & 109 \\
2008 & 47.277 & 3.093 & 944 & 441 & 286 & 169 & 117 \\
2009 & 50.587 & 3.309 & 1.010 & 472 & 306 & 181 & 125 \\
2010 & 54.128 & 3.541 & 1.080 & 505 & 328 & 194 & 134 \\
Total & & & 5.510 & 2.575 & 1.671 & 987 & 683 \\
\hline
\end{tabular}

Notas: (1) El cuadro muestra la inversión adicional necesaria para satisfacer el incremento de la demanda por energía de cada año para que no ocurra racionamiento, a menos que la sequía sea más severa que la del año hidrológico 1998-99. (2) En cada caso se supone que el precio de largo plazo de la electricidad se ajusta para rentar a la tecnología de expansión.

i) Se ha supuesto que el consumo crece $7 \%$ todos los años, a partir de los 33.708 GWh de 2003. Este consumo se obtuvo de las Estadísticas de Operación del CDEC-SIC. El consumo incluye las pérdidas de transmisión.

ii) El factor de disponibilidad en hidrología seca se supone igual a 37\%. Vale decir, durante una hidrología seca una central hidráulica opera al $37 \%$ de su capacidad máxima. Este factor es el mismo que se observó en 1999. Para obtener la inversión adicional se dividió el aumento de la demanda del año por el factor de carga y el número de horas del año, es decir: [columna (2)] $/(0,37 \times 8.760$ horas $)$.

iii) El factor de disponibilidad de una planta de carbón se supone igual a $80 \%$ (el informe de precio de nudo de la CNE de abril de 2004 supone que la disponibilidad es 90\%). Para obtener la inversión adicional se dividió el aumento de la demanda del año por el factor de carga y el número de horas del año, es decir: [columna (2)]/(0,80×8.760 horas).

iv) El costo anual monómico por KWh hidráulico se supuso igual a US\$34/MWh. El costo total reportado en la columna (5) es US\$ 34/MWh $\times$ [columna (2)] /0,37. El factor de planta utilizado para obtener el costo monómico es $86 \%$.

v) El costo anual monómico de una central de carbón se supuso igual a US\$43,7/ MWh. El costo total reportado en la columna (5) es US\$ 43,7/MWh $\times$ [columna (2)] $/ 0,80$. El factor de planta utilizado para obtener el costo monómico es $86 \%$. 
inversión adicional en MW si el sistema se expandiera con capacidad hidráulica, y la columna 4 si lo hiciera con centrales de carbón. Las columnas 4 y 5 valoran el costo adicional del abastecimiento con una u otra tecnología, que incluye la inversión y la operación.

Grosso modo, para conseguir el mismo nivel de seguridad se requiere más del doble de capacidad adicional si el sistema se expande con centrales hidráulicas; el costo de abastecimiento sería alrededor de $70 \%$ más alto. En conclusión:

Hecho 5. La hidroelectricidad no es la tecnología de expansión del sistema.

El otro riesgo: precios volátiles. Sabido es que los precios del petróleo y del carbón son muy volátiles. Sin embargo, la disponibilidad de petróleo y carbón es segura. La seguridad no se debe a que los importemos de países particularmente estables ${ }^{14}$, sino a que se trata de commodities con mercados profundos. Por ejemplo, cuando Enap licita crudo, recibe ofertas por 4 ó 5 veces el volumen solicitado, desde las más diversas fuentes.

Hecho 6. Los precios del carbón y del petróleo son muy volátiles. Su disponibilidad, por contraste, es menos volátil.

Como se dijo en la introducción, la disponibilidad segura de carbón y petróleo implica que si la demanda fuera completamente insensible al precio, se podría continuar consumiendo las mismas cantidades aun si ocurriese un shock petrolero. (Por supuesto, en la práctica las demandas no son perfectamente inelásticas, y la cantidad demandada cae cuando aumenta el precio.) Cuando se trata de agua o gas natural, por contraste, el consumo tiene que caer cuando cae la oferta, por la simple razón de que en ese caso la restricción es física. Ésa es la causa material de las crisis de abastecimiento eléctrico en el SIC. Las causas eficientes las discutiremos a continuación.

\section{El problema de fondo: combustibles de disponibilidad volátil, riesgos no asignados y precios inflexibles}

Una mirada al Gráfico $\mathrm{N}^{\circ} 3$ indica que el abastecimiento de electricidad a todo evento está más allá de las posibilidades del sistema eléctrico

\footnotetext{
${ }^{14}$ Por ejemplo, alrededor del $50 \%$ del petróleo que importó Chile durante el primer trimestre de 2004 provino de Argentina (i!), un 15\% de Brasil, y el resto de Perú, Nigeria y Gabón (comunicación personal de Daniel Fernández, ex gerente general de ENAP).
} 
chileno, si por ello se entiende consumo constante a precios constantes ${ }^{15}$. Simplemente, la hidrología es muy variable. En esta sección describiremos el sistema de precios vigente actualmente, y señalaremos por qué es inadecuado para acomodar la volatilidad de la disponibilidad de gas natural, agua o cualquier otro combustible.

\subsection{El sistema de precios chileno}

En el sistema eléctrico interactúan tres mercados a los que concurren generadores, distribuidores y usuarios para intercambiar energía y potencia: (a) el mercado de intercambios instantáneo o spot, donde los generadores transan energía y potencia al precio spot; (b) el mercado regulado, donde las distribuidoras compran por medio de contratos de mediano y largo plazo al precio de nudo, fijado cada seis meses por la Comisión Nacional de Energía (CNE), y (c) el mercado libre, donde los grandes usuarios pueden contratar con generadores o distribuidores en condiciones no reguladas de precios y calidad de suministro y los precios son libres. A continuación describimos cada uno y argumentamos que el precio de nudo, que pagan los usuarios regulados, es la fuente de los problemas y explicamos por qué una escasez de insumo puede devenir en crisis.

\subsubsection{El mercado spot}

Para asegurar que el sistema eléctrico opere al mínimo costo, el Centro de Despacho Económico de Carga (conocido por CDEC) despacha las centrales en estricto orden de mérito, vale decir, las ordena de menor a mayor costo de operación. Primero entran en funcionamiento las centrales hidráulicas de pasada. Su costo de operación es prácticamente cero porque no pueden embalsar agua. Por lo tanto, si el agua no se usa en el momento en que pasa por la central, se pierde. Si la cantidad producida por centrales de pasada no es suficiente, entran en funcionamiento centrales térmicas en orden creciente de costos de operación. El costo de operación de cada central térmica depende del precio del combustible que quema y de la

15 Obviamente, siempre es posible invertir en el sistema lo suficiente para que la probabilidad de falla sea nimia. Sin embargo, tal cosa sería económicamente insensata. Galetovic et al. (2002b) estimaron que para eliminar los déficits debidos a sequías, y suponiendo que nunca ocurra una sequía peor que la de 1998-1999, se necesita invertir del orden del 20\% de la capacidad instalada actualmente. Esto se justificaría sólo si el costo de falla fuera a lo menos cinco veces el costo estimado actualmente. 
eficiencia con que transforma calor en energía eléctrica ${ }^{16}$. Como se aprecia en el Gráfico $\mathrm{N}^{\circ} 4$, el orden de mérito dibuja una curva de oferta.

Las órdenes del CDEC son obligatorias e independientes de los contratos de comercialización de cada empresa. Por ello, es frecuente que existan transferencias entre generadores, las que se valoran al costo marginal instantáneo del sistema. Esta separación entre despacho y contratos permite que el sistema minimice el costo total de producción en cada instante. Por ejemplo, consideremos un generador que ha contratado la venta de energía pero que por tener un costo marginal de producción alto no será despachado. Este generador está obligado a comprarles a generadores de menor costo de operación para cubrir su déficit. Pese a ser obligatoria, la transacción es comercialmente atractiva para este generador, porque le permite comprar energía de productores con menor costo de operación que el propio. Mensualmente el CDEC entrega un balance de compras y ventas entre generadores.

GRÁFICO N ${ }^{\circ}$ : DETERMINACIÓN DEL PRECIO SPOT

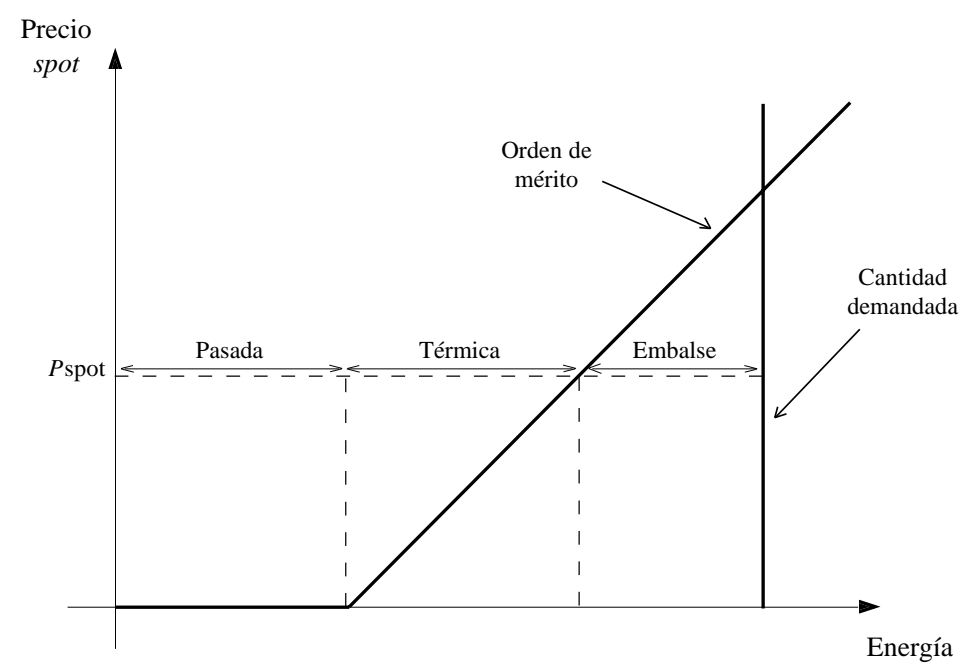

${ }^{16}$ Las centrales hidráulicas con embalses pueden almacenar agua y sustituir generación térmica cuando sea más beneficioso para el sistema. Por lo tanto, el costo de oportunidad de generar con agua embalsada hoy es no poder sustituir generación térmica mañana. Así, este costo de oportunidad dependerá de la escasez o abundancia del agua. 


\subsubsection{El mercado regulado}

El precio de nudo de la energía. El precio spot está sujeto a fuertes variaciones, aun durante períodos cortos (véase el Gráfico $\mathrm{N}^{\circ}$ 5). Cuando se hizo la ley en 1982 se pensó que las variaciones de esa magnitud eran inaceptables para usuarios residenciales y empresas pequeñas. Por eso se reguló el precio al cual los distribuidores la venderían a los usuarios cuya potencia instalada era menor que dos MW. En enero de este año se aprobó la "ley corta" y el límite se disminuyó a 500 KW"17.

Aproximadamente el $68 \%$ de la energía vendida en el SIC es comercializada por distribuidoras. El resto lo venden directamente los generadores a cerca de 50 clientes de gran tamaño. Las ventas de generadores a distribuidores se valoran al precio de nudo fijado cada seis meses en abril y octubre y corresponde, en términos simples, al promedio de los precios

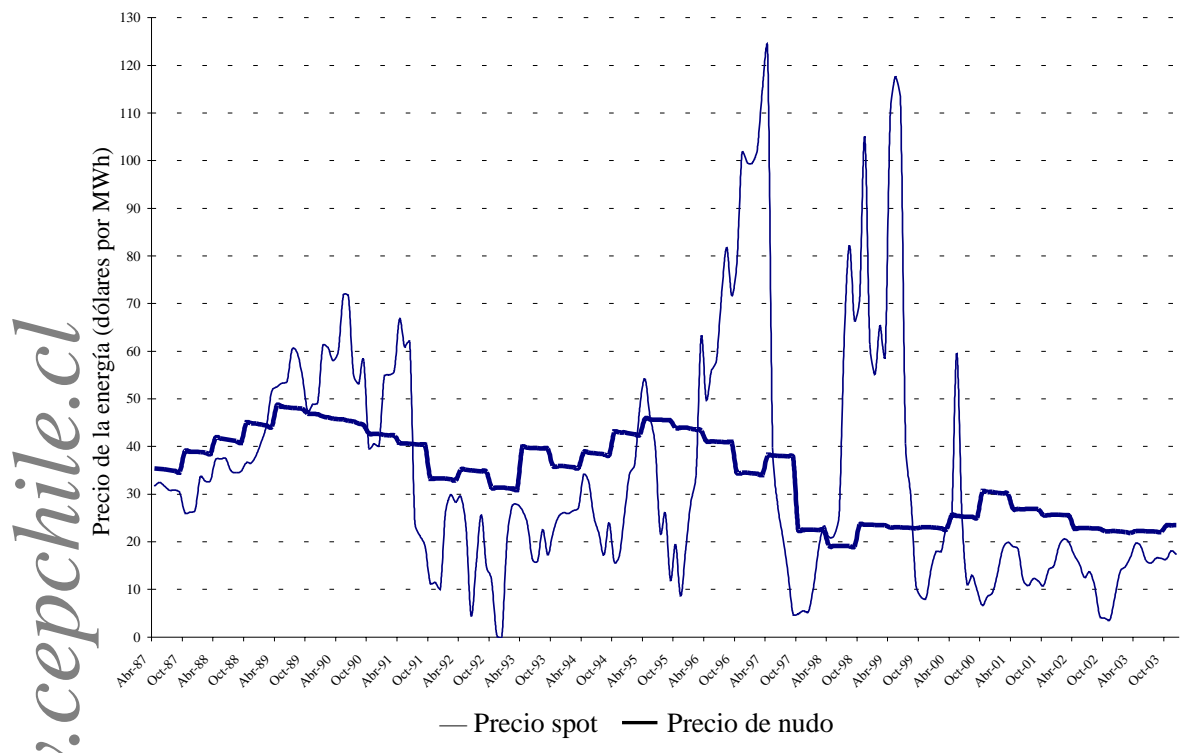

${ }^{17}$ Dos MW equivalen a un centro comercial pequeño. $500 \mathrm{KW}$ equivalen aproximadamente a un hotel grande, un supermercado o un edificio de oficinas. 
spot esperados para los siguientes 16 trimestres, incluyendo los costos de falla de energía en casos en que el modelo prediga racionamiento ${ }^{18}$.

Para fijar el precio de nudo la CNE utiliza un modelo de programación dinámica estocástica llamado GOL (por gestión óptima del Laja) ${ }^{19}$. Sobre la base de proyecciones de la demanda por energía y potencia de punta para los próximos 10 años, este modelo encuentra el uso del agua del lago Laja que minimiza el costo esperado de abastecimiento y de falla, dados la cota inicial del lago Laja, las centrales existentes, la entrada óptima de centrales en el horizonte de 10 años y las líneas de transmisión troncal proyectadas ${ }^{20}$. La incertidumbre hidrológica se modela con 40 hidrologías supuestas equiprobables.

El precio que pagan los usuarios regulados. Dijimos que las distribuidoras compran energía y potencia a precio de nudo. A este precio le agregan el cobro por las instalaciones de distribución (el así llamado "valor agregado de distribución" o VAD), que se fija cada cuatro años y, a partir de 2004, un cargo fijo por uso del sistema troncal de transmisión. De la suma resulta el precio a usuario de la electricidad ${ }^{21}$.

En principio, la tarifa debiera cobrar separadamente la conexión a la red (el uso de los cables), por un lado, y la energía y la potencia, por el otro. El cargo de conexión fijo pagaría el VAD, mientras que la tarifa de energía y potencia simplemente traspasaría los respectivos precios de nudo. Esto reconocería que, en realidad, las distribuidoras actúan en dos roles, como distribuidores y como comercializadores.

En la práctica, sin embargo, la "suma" es más compleja y se funden los tres cargos. Es cierto que los usuarios de cierto tamaño pueden elegir tarifas que cobran la energía, potencia y VAD por separado. Pero en realidad la inmensa mayoría de los usuarios residenciales paga la tarifa BT-1, un precio uniforme por KWh que ni siquiera distingue entre energía y potencia $^{22}$. La consecuencia es que el precio marginal de la energía es algo

${ }^{18}$ Independientemente del resultado que arroje el modelo, la ley no permite que el precio de nudo resultante difiera en más de $5 \%$ de los precios libres; si el precio simulado sobrepasa los márgenes, el precio de nudo se fija en dicho límite.

${ }^{19}$ A partir de 2004, la CNE calculará el precio de nudo de la energía con el modelo de programación dinámica dual estocástica, multinodal y multiembalse OSE 2000 (por operación de sistemas eléctricos 2000).

${ }^{20}$ Este plan, que es sólo indicativo, se conoce por plan de obras. Es importante notar que la ley no impone ninguna obligación de inversión, salvo las nuevas instalaciones en transmisión que, con la aprobación de la ley 19.940, son ahora obligatorias y licitadas.

${ }^{21}$ Sobre la regulación de distribución véase a Rudnick y Raineri (1997), Molina (1998), Bernstein (2000) y Bustos y Galetovic (2002). Además, en el Apéndice D describimos brevemente la tarificación de distribución.

${ }^{22}$ En 2004 pagaban la tarifa BT1 alrededor de 4,5 millones de clientes que consumen $7.600 \mathrm{GWh}$, cerca del $23 \%$ de la energía vendida en el SIC. 
más de dos veces el precio de nudo monómico. Veremos en la sección 5 que la magnitud de la ineficiencia que causa este precio marginal alto es apreciable.

Por supuesto, esto no implica que los usuarios necesariamente estén pagando más que lo que cuesta lo que consumen, porque la tarifa que se fija cada cuatro años se calcula de manera tal que, en principio, los ingresos totales de la distribuidora serán suficientes para cubrir sus costos y sólo obtener una rentabilidad normal sobre el capital.

El sistema de precios en escasez. Nótese que el precio de nudo es fijo por seis meses y, más aún, corresponde al promedio de los costos marginales, incluyendo las fallas, esperados en los próximos 16 trimestres (cuatro años). En consecuencia, no es un precio diseñado para reflejar las condiciones contingentes de oferta y demanda. Cuando, por ejemplo, ocurre una sequía o un corte de gas y es necesario racionar, el precio que enfrentan los usuarios sigue siendo el mismo, pero aumentado por las así llamadas compensaciones por energía no servida, responsables de transmitirle el costo de oportunidad de la energía no suministrada a los usuarios durante una escasez.

¿En qué consiste este mecanismo? Normalmente la cantidad demandada al precio regulado es menor que la capacidad disponible, y en esas condiciones no es indispensable que los usuarios enfrenten el costo marginal de la energía en cada momento para evitar cortes y racionamientos. Sin embargo, durante los episodios de escasez es físicamente imposible satisfacer la demanda al precio de nudo, y el sistema contempla el pago de compensaciones. En efecto, los usuarios regulados pagan el costo de falla en el precio de nudo (en aquellos casos en que las simulaciones del modelo GOL las arrojan) y luego, en teoría, los generadores con déficits los compensan por la energía no suministrada cuando el sistema no es capaz de abastecer la totalidad de la cantidad demandada de energía y se dicta un decreto de racionamiento. Por cada KWh no suministrado el generador deficitario debe pagarle al usuario la diferencia entre el costo de falla y el precio de nudo.

Por supuesto, si hay racionamiento es imposible determinar con certeza el monto de la energía no entregada. Por lo tanto, en la práctica ésta se define como la diferencia entre la energía facturada durante el mismo período del año anterior (aumentada por la tasa de crecimiento esperada de la demanda incluida en la última fijación del precio de nudo) y la energía efectivamente entregada. Es decir, la compensación es 
$\left[\left(1+g_{t}\right) \cdot(\text { energía facturada })_{t-1}-(\text { energía entregada })_{t}\right] \times\left[\right.$ costo de falla $\left.-p_{N}\right]$,

donde $g_{t}$ es la tasa de crecimiento de la demanda incluida en la última fijación del precio de nudo y $p_{N}$ es el precio de nudo.

Se puede demostrar que bajo ciertas condiciones hipotéticas este mecanismo puede replicar la asignación de energía que ocurriría si existiera un precio flexible ${ }^{23}$. El porqué se puede apreciar en el Gráfico $\mathrm{N}^{\circ} 6$. Supóngase que hay $x(t) \mathrm{KWh}$ de energía disponibles, cantidad que es menor que la energía demandada al precio de nudo $p_{N}, x^{d}\left(p_{N}\right)$. Si el costo de falla estimado por el regulador es igual a $\mathrm{D}^{-1}[x(t)]$, es decir, precio que eliminaría el exceso de demanda, y $\left(1+g_{t}\right) \cdot x(\mathrm{t}-1)$ es suficientemente grande, entonces el costo de oportunidad de consumir un KWh adicional es igual al costo de falla: si consume un KWh adicional paga $p_{N} \mathrm{y}$ deja de recibir (costo de falla $-p_{N}$ ).

El mecanismo descrito, sin embargo, tiene una serie de defectos prácticos que lo hacen inflexible para administrar adecuadamente una escasez, los que detallaremos a continuación.

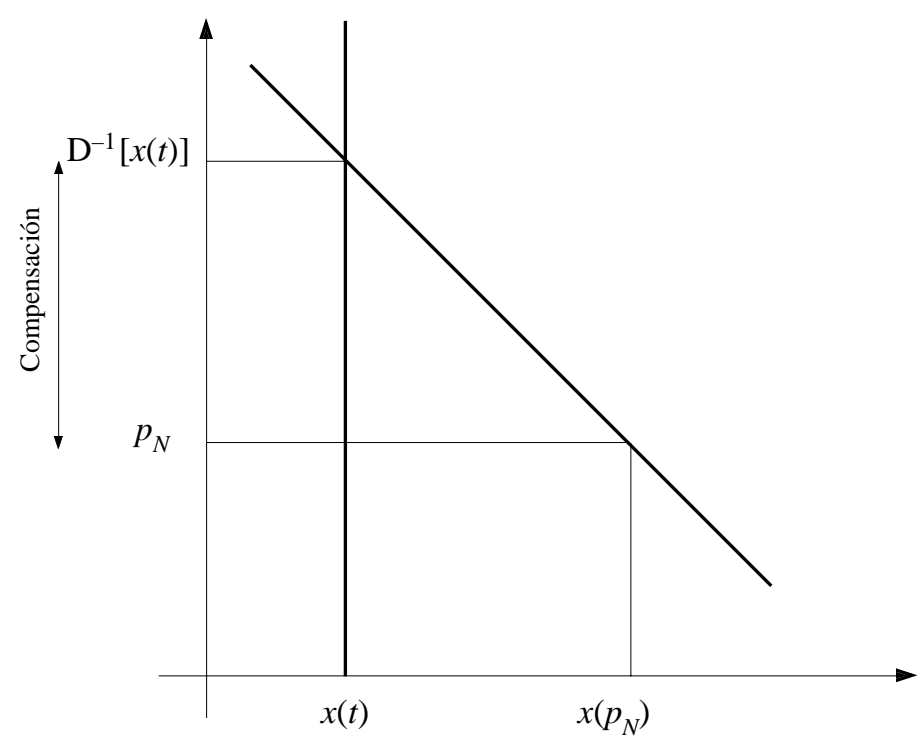

${ }^{23}$ Véase Serra (1997) y Díaz et al. (2001). 


\subsection{Los defectos del actual sistema de precios}

El precio de nudo y su mecanismo de compensación asociado tienen varios defectos, y por ello una escasez de gas bien puede devenir en crisis. Es conveniente separar estos defectos en dos categorías: aquellos que impiden distribuir eficientemente los riesgos asociados a la disponibilidad incierta de insumos y aquellos que transforman una escasez en crisis.

\subsubsection{Distribución inadecuada y rígida de riesgos}

Es sabido que la volatilidad del suministro de gas no está incorporada en el precio de nudo. En principio, ésta podría incorporarse en el cálculo de los precios de la energía y de la potencia, tal como se hace con el agua. Pero, a diferencia del agua, no existe manera razonable, mucho menos verificable, de estimar la distribución de probabilidades de los cortes de gas natural-éstos dependen en gran medida de las veleidades del ciclo político argentino-. Por eso:

Defecto 1: Actualmente el precio de nudo no incorpora la incertidumbre del abastecimiento del gas; es materialmente muy difícil representar esa incertidumbre con una distribución de probabilidades deducida de la historia.

Este solo hecho destaca una de las limitaciones fundamentales de las propuestas que simplemente le "suman" la volatilidad de la disponibilidad de gas natural al modelo de precios vigente: esto es, su aplicación requiere una decisión discrecional de la autoridad que, en realidad, siempre va a ser muy discutible, aunque no por ello menos determinante.

En el fondo, el problema es que para calcular el precio de nudo el regulador tiene que decidir y cuantificar los distintos riesgos inherentes del abastecimiento eléctrico. Una vez que se decide por una distribución de probabilidad, el contrato distribuye estos riesgos de una sola forma e impone una sola condición de abastecimiento. Por último, al ponerle precio, el regulador también decide cuánto cuestan esos riesgos. En consecuencia:

Defecto 2: El contrato impide que evalúen y tomen los riesgos quienes estén mejor capacitados para cubrirlos. Además, al imponer una sola condición de abastecimiento, impide que los usuarios elijan la manera más barata de cubrirse. 
Es importante recalcar que imponer una sola condición de abastecimiento y distribución de riesgos es parte central del problema. Por un lado, es evidente que distintos clientes tienen preferencias distintas. Algunos (por ejemplo una clínica) posiblemente estarán dispuestos a pagar más caro por consumir como si no hubiera episodios de escasez; a otros les resultará muy barato ajustarse ocasionalmente y consumir poco en escasez; y seguramente muchos querrán contratar parte del suministro a todo evento y otra parte contingente a la situación de abastecimiento. Esto no refleja sino que el costo de restringir el consumo de electricidad varía considerablemente entre los distintos usuarios, como lo demostró hace años el estudio de Fierro y Serra (1997).

Por último, el contrato regulado es difuso. ¿Por qué? En principio, impone determinada calidad de servicio — a los usuarios no se les puede cortar el suministro, salvo decreto de racionamiento mediante y, en ese caso, se les debe compensar a costo de falla-. Sin embargo, en la práctica las condiciones del contrato no quedan escritas sino hasta que se dicta el decreto de racionamiento; sólo ahí se asignan los riesgos. En otras palabras, se requiere interpretación del regulador, quien no deja por escrito cuáles son sus criterios, precisamente para poder decidir a discreción según la situación. En los hechos, las discrepancias frecuentemente terminan en los tribunales, pero es muy improbable que un tribunal falle en contra del regulador ${ }^{24}$.

\section{Defecto 3: El contrato regulado es difuso.}

Se suele afirmar que la solución es sustituir el precio de nudo por el promedio de los precios libres. La manera políticamente viable de ponerla en práctica consiste en imponer una banda aún más estrecha que el 5\% vigente. La virtud de esta solución es que el promedio de los precios libres está directamente relacionado con el costo promedio de producir electricidad a nivel de generación. Los defectos son varios: el factor de carga de los clientes libres es menor que el de clientes regulados ${ }^{25}$; las condiciones de los contratos libres son distintas; se sigue imponiendo a los clientes de menos de $500 \mathrm{KW}$ una sola distribución de riesgos (que esta vez refleja el precio promedio que obtienen los clientes libres), y las condiciones de abastecimiento siguen siendo las mismas. Más aún, el precio de nudo influ-

${ }^{24}$ Es posible que este problema se modere con el nuevo Comité de Expertos, aunque no es rol del Comité escribir las reglas sino zanjar disputas.

${ }^{25} \mathrm{El}$ factor de carga de un cliente es la razón de la cantidad demandada promedio a la cantidad demandada máxima. Mientras mayor sea el factor de carga, más barato es abastecer a un cliente. 
ye en los precios libres (es la referencia a partir de la cual negocian los clientes). Por último, la asignación de riesgos sigue siendo difusa porque el decreto de racionamiento sigue siendo central —nada cambia simplemente por tomar otro precio de referencia-.

Hecho 7. La sustitución del precio de nudo por el promedio de los precios libres no corrige los defectos del actual sistema de precios.

\subsubsection{De la escasez a la crisis}

El mecanismo de compensaciones tiene varios defectos que algunos autores han discutido. Primero, es muy rígido y, para funcionar, requiere de intervención regulatoria muy hábil. Sin embargo, si el pasado sirve de guía, no es razonable esperar que la intervención regulatoria esté a la altura de las circunstancias ${ }^{26}$. Más aún, en el pasado las condiciones bajo las cuales se debe compensar han sido desafiadas por las empresas en los tribunales. Cuando esto ocurre, el mecanismo deja de cumplir su rol de transmitirles el costo de oportunidad de la energía a los usuarios y el sistema de precios queda incompleto. En ese caso el costo de oportunidad de consumir energía en escasez sigue siendo el mismo que en tiempos normales, y la crisis es inevitable.

Defecto 4: El mecanismo de compensaciones es difícil de administrar y cuando no funciona, el sistema de precios queda incompleto.

El segundo defecto es que la compensación se calcula promediando el costo de falla de distintos usuarios, residenciales, industriales y comerciales, ignorando que, como lo han demostrado Fierro y Serra (1997), existe gran dispersión que refleja que hay usuarios que podrían disminuir su consumo a menor costo que otros.

El tercer defecto es práctico. El costo de falla utilizado para calcular las compensaciones y valorar las transferencias en el mercado spot supone que durante una escasez la igualdad de consumo y disponibilidad de energía se alcanza porque todos los consumidores disminuyen su consumo en la misma proporción (v. gr., 4\%); a esto lo llamaremos de aquí en adelante racionamiento parejo ${ }^{27}$. Sin embargo, veremos más adelante que el costo

${ }^{26}$ Sobre la actuación del regulador durante la crisis pasada, véase Díaz et al. (2000) y Fischer y Galetovic (2003). Algunos de los defectos que causaron la crisis anterior han sido corregidos, pero otros persisten.

${ }^{27}$ Es importante mencionar que el racionamiento parejo no implica cortes de suministro: la disminución pareja basta para compensar el déficit de abastecimiento. El costo de racionar mediante cortes es aún mayor. 
sería mucho menor si se disminuyera el consumo eficientemente, vale decir, subiendo por la curva de demanda y dejando de consumir aquellos KWh que valen menos. Puesto de otra forma, si el mecanismo de compensaciones se aplica tal como se describe en el Gráfico $\mathrm{N}^{\circ} 6$ y el costo de falla usado para compensar es lo que cuesta el racionamiento parejo, la disminución de consumo sería considerablemente mayor que la necesaria para ajustarse al déficit.

El Gráfico $\mathrm{N}^{\circ} 7$ permite apreciar lo anterior. El estudio de Benavente et al. (2004) estima la elasticidad de la demanda por electricidad residencial y permite calcular en cuánto caería el consumo si los hogares fueran compensados por disminuir su consumo, en cuyo caso el costo de oportunidad de consumir un KWh sería igual al costo de falla. Se aprecia que al cabo de nueve meses el consumo disminuiría más de $18 \%$, y durante los nueve meses sumados la caída sería poco más de $12 \%$ (ésta no se muestra en el gráfico). Sin embargo, entre septiembre de 1998 y junio de 1999 se racionaron apenas $450 \mathrm{GWh}$, equivalentes al 2,5\% del consumo total. Esto indica que el costo de una restricción mediante racionamiento parejo es apreciablemente mayor, tema al que volveremos líneas abajo.

GRÁFICO N ${ }^{\circ}$ 7: CAÍDA DEL CONSUMO SI DURANTE UNA ESCASEZ LA ENERGÍA CUESTA EL COSTO DE FALLA (US\$ 0,21/KWh)

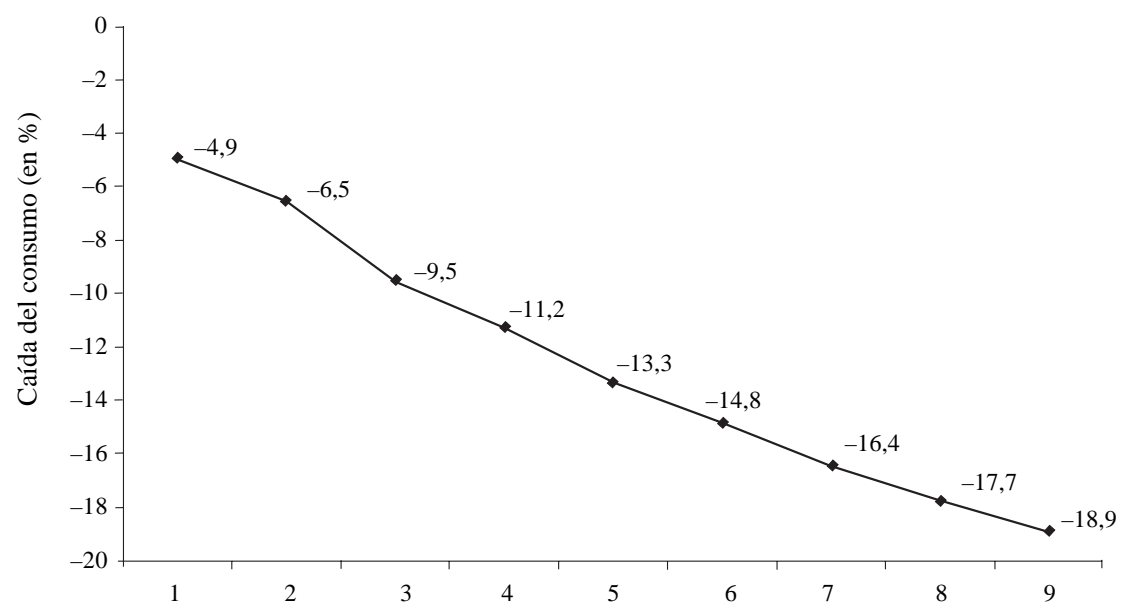

Meses después del aumento del costo de oportunidad de la energía 
Defecto 5: El costo de una restricción materializada mediante racionamiento parejo es apreciablemente mayor que el costo de una restricción eficiente. Porque las compensaciones son inflexibles, el precio de nudo impide que los usuarios contraten libremente sus restricciones de consumo en escasez.

\section{Una propuesta para solucionar el problema de fondo: Hacia un multicarrier de la electricidad}

\subsection{Cómo solucionar el problema: Conceptos}

Vimos en las dos secciones precedentes que todos los combustibles para generar electricidad son volátiles. La disponibilidad de petróleo y de carbón es bastante segura (de no mediar, por supuesto, una guerra mundial que interrumpa el comercio internacional), pero sus precios son muy volátiles. El agua y el gas natural, por contraste, son combustibles cuya disponibilidad es volátil; aun si la demanda fuera completamente inelástica al precio, el consumo tiene que ajustarse cuando ocurre una escasez por mera indisponibilidad física.

De lo anterior se sigue que el sistema de precios y contratos eléctricos debiera ser suficientemente flexible para lograr tres cosas. Primero, distribuir los riesgos de costo por medio de contratos. Cuando aumenta el precio del carbón, o hay menos agua disponible, el costo de oportunidad o económico de generar electricidad es mayor, y lo opuesto ocurre cuando el carbón cuesta menos o hay más agua. Este riesgo debe repartirse entre generadores, comercializadores y clientes por medio de contratos.

Segundo, las preferencias de los usuarios debieran reflejarse en contratos que finalmente determinan la composición de la generación. Por ejemplo, aquellos usuarios que quieran consumir como si los episodios de escasez no existieran tendrán que pagar más caro porque sus contratos deben respaldarse con centrales que usen combustibles cuya disponibilidad no es volátil, v. gr., petróleo o carbón. Quienes estén dispuestos a disminuir su consumo durante una escasez de gas se beneficiarán con precios más bajos, pero asumirán los costos de ajustar ocasionalmente su consumo.

Tercero, la disponibilidad incierta de gas y agua implica que en algunos años habrá más energía que en otros. Por ejemplo, como se puede apreciar del Gráfico $\mathrm{N}^{\circ} 3$, la misma capacidad hidráulica instalada permite generar cerca de $35.000 \mathrm{GWh}$ en un año hidrológico muy húmedo, como el de 1972-1973, pero menos de un tercio en un año muy seco como 19981999. De manera similar, la misma capacidad instalada de ciclos combina- 
dos puede generar menos en un año en que la política argentina de precios internos del gas sea populista (v. gr., 2004) que en otro en que los precios sean libres (v. gr., 1999). Por eso, deben existir mecanismos que permitan disminuir eficientemente la cantidad demandada en años de escasez.

Una manera de distribuir claramente los riesgos y asignar la energía eficientemente cuando haya escasez de agua o gas es que los usuarios paguen el precio spot de la energía en todo momento. Así, por ejemplo, en un año seco el precio al cliente final sería alto y el consumo disminuiría hasta igualarse con la energía disponible, y lo contrario ocurriría en un año húmedo. Al mismo tiempo, los riesgos estarían claramente asignados: las fluctuaciones del costo de la electricidad serían absorbidas íntegramente por los clientes finales. En esencia, este modelo opera en el mercado de la bencina y el diésel: cuando aumenta el precio del petróleo, son más caros. Los usuarios compran combustibles de precio volátil, asumen el costo de la volatilidad y ajustan su consumo según sea el precio.

Que los usuarios paguen el precio spot tiene dos defectos, sin embargo. El primero es que hay maneras más convenientes y baratas de distribuir los riesgos. Nuevamente, se trataría de un solo contrato y condición de abastecimiento. El segundo es que todos los generadores ganan si se coluden para aumentar el precio spot, lo que hoy no es así porque los contratos con el cliente final son a precio fijo ${ }^{28}$.

En el sector eléctrico la solución va por un lado distinto. En primer lugar, debe haber libertad para contratar condiciones de abastecimiento que reflejen diversas preferencias por riesgo. Algunos estarán dispuestos a pagar caro para nunca disminuir su consumo; estos contratos deberían estar respaldados por centrales a carbón. Otros seguramente preferirán pagar menos, aunque de vez en cuando deban disminuir en algo su consumo; estos contratos se pueden respaldar con centrales de gas natural o hidráulicas. En realidad, nada dice que a un cliente no le convenga contratar una parte de su consumo a firme pagando caro, dejando la posibilidad de restringir parte de su consumo ocasionalmente. Y, además, seguramente muchos clientes valorarán los precios estables.

En segundo lugar, con la excepción que mencionaremos más adelante, las condiciones de los contratos no debieran ser dictadas por un

\footnotetext{
${ }^{28}$ Esta afirmación amerita una explicación. Hoy en día casi todas las ventas que hacen los generadores a distribuidoras y clientes libres son a precios que no varían con el precio spot. Al mismo tiempo, las reglas de despacho implican que siempre un generador está comprando en el spot, mientras que otro está vendiendo. El que compra quiere que el precio spot sea lo más bajo posible, porque vende a precio de contrato; todo aumento del precio spot disminuye sus utilidades. Por contraste, si los usuarios pagan el precio spot, todos los generadores ganarían aumentándolo, pues todos venden más caro. Sobre la relación entre contratos e incentivos para explotar poder de mercado, véase Arellano (2004).
} 
regulador, el que tampoco debiera fijar los precios de la energía y de la potencia. Por supuesto, esto supone que los mercados de generación y comercialización de energía son competitivos. Argumentaremos líneas abajo que es razonable pensar que lo son, si uno está dispuesto a separar la comercialización de energía de la distribución —es decir, separar los cables de la electricidad que conducen-.

En condiciones como las descritas, la mezcla de tecnologías para generar electricidad saldrá de las preferencias de los usuarios, reflejadas en los contratos que tomen. Al mismo tiempo, en condiciones de escasez de agua, gas natural o cualquier otro combustible cuya disponibilidad sea volátil, los contratos especificarán quién debe restringir su consumo. Finalmente, el riesgo de precios de insumos, tales como carbón o petróleo, también se distribuirá según los contratos.

A continuación propondremos un mecanismo para poner esto en práctica.

\subsection{Cómo solucionar el problema: Propuesta}

Nuestra propuesta tiene cuatro partes. La primera es crear un mercado de comercialización competitivo y separado de la distribución. La segunda propone un contrato para usuarios pequeños poco sofisticados (el contrato para la señora Juanita). La tercera parte es la regulación prudencial necesaria para que la liberalización funcione. La última parte propone mantener el modelo de despacho por orden de mérito a costo variable —el actual mercado spot-.

\subsubsection{Creando el mercado de la comercialización}

Vimos que el problema hoy en día es que el contrato disponible en el mercado, el precio de nudo, es inflexible. Aunque éste considera que ocasionalmente hay escasez por falta de agua, las compensaciones son engorrosas y no han operado bien porque la asignación de los riesgos no es clara. Más aún, el precio lo fijan ya sea la autoridad o, cuando opera la banda, los contratos libres, que firman clientes cuyas características son distintas de las de los consumidores más pequeños.

Para introducir contratos flexibles es necesario eliminar el precio de nudo y sustituirlo por contratos libres que se adapten a las necesidades de clientes diversos. Esto, sin embargo, es impracticable bajo el actual esquema de comercialización a través de las distribuidoras, porque si la tarea se delega al distribuidor, éste explotará su poder de mercado. Al final, termi- 
naríamos con un regulador visando contratos o, peor aún, diseñándolos y poniéndoles precio-que es precisamente lo que causa el problema que estamos tratando de resolver-.

Los contratos flexibles no se pueden entregar a las actuales distribuidoras porque la distribución es un monopolio natural que debe seguir con regulación, tal como hasta ahora. En la comercialización de energía, por contraste, no hay economías de escala significativas y se puede confiar en que la competencia puede impedir la explotación del poder de mercado. Por eso, nuestras primeras dos propuestas son las siguientes:

Propuesta 1: Separar la distribución de energía y potencia (transporte en tensión media y baja) de la comercialización de energía. Introducir un precio de distribución para cada usuario separado de la cuenta de energía y de la de potencia. Este cargo es el VAD de distribución actual, que se calcularía igual que ahora.

Propuesta 2: Abrir la comercialización de energía y potencia a empresas especializadas.

¿Quién podría ser comercializador? En nuestra opinión, la entrada debiera ser libre. Seguramente algunos argumentarán que conviene separar completamente la distribución de la comercialización. El temor es que una distribuidora podría extender su poder de mercado hacia la comercialización y deteriorar la calidad del servicio a los clientes de otros comercializadores $^{29}$. Nuestra opinión al respecto no es definitiva, pero por ahora pensamos que seguramente la prohibición de participar en comercialización es más drástica que lo necesario. Probablemente sea deseable que las actuales distribuidoras puedan entrar en comercialización de modo que, por ejemplo, Chilectra entre en la zona de Chilquinta, y viceversa. Aunque, de ser así, tal vez sea conveniente desarrollar normas específicas que sancionen la discriminación. Es indispensable, además, que cada cliente tenga un cargo separado de distribución que aparezca mes a mes en su cuenta, contrariamente a lo que ocurre ahora. De aquí nuestra siguiente propuesta:

Propuesta 3: Permitirles a las actuales distribuidoras seguir participando en la comercialización, pero creando empresas especializadas y separadas de la distribuidora.

Más allá de eso, la entrada a este negocio debiera ser libre para cualquiera que cumpla con los requisitos prudenciales que describiremos

\footnotetext{
${ }^{29}$ Sobre el particular véase a Galetovic (2003).
} 
líneas abajo. Esto incluye a los generadores, pero también a cualquier otro tipo de empresa. Por ejemplo, seguramente sería un negocio atractivo para empresas de teléfono, TV cable o agua, las que podrían aprovechar economías de ámbito en medición y facturación. También podrían ingresar las grandes tiendas tales como Falabella, Ripley o Almacenes Paris. El punto de fondo es que nada sugiere que existan economías de escala en comercialización, y por eso la entrada debiera ser libre.

Al mismo tiempo, si el mercado de comercialización es competitivo, los clientes debieran quedar protegidos del ejercicio de poder de mercado. No se justificarían, entonces, que el precio a usuario final se siga regulando, ni la actual separación de clientes libres y regulados. Con la excepción que discutiremos a continuación, nuestra cuarta propuesta es la siguiente:

\section{Propuesta 4: Eliminar el límite de clientes libres.}

\subsubsection{Haciéndose cargo de la señora Juanita}

Se podría argumentar que la señora Juanita no es suficientemente sofisticada para entender un mercado libre de energía. Seguramente tal afirmación es factualmente correcta, pero ciertamente dudosa si se trata de justificar la regulación. Por ejemplo, la mayoría no "entiende" el mercado de la telefonía móvil, tampoco cómo funcionan los teléfonos, pero eso no impide que las empresas compitan intensamente y se esfuercen por diseñar planes que se ajusten a las necesidades y preferencias de los clientes. Sea como fuere, se suele afirmar que la liberalización podría desproteger a la señora Juanita y la propuesta que sigue se hace cargo de esta preocupación.

Actualmente la señora Juanita adhiere al contrato regulado. Como ya se vio, este contrato especifica una regla para calcular el precio y una lista de condiciones de servicio. Una de estas condiciones es que no se puede racionar a menos que lo autorice un decreto, y en ese caso los usuarios deberían ser compensados a costo de falla.

Ya discutimos sobre las rigideces del mecanismo de compensación. El segundo defecto es que actualmente el precio de nudo lo fija un regulador y nada garantiza que refleje con precisión el costo de servir el contrato regulado. Esto es así aun si el precio termina siendo fijado por los contratos libres.

Propuesta 5: Diseñar un contrato "regulado" para la señora Juanita cuyas características las fije el regulador y que le garantice suministro a todo evento. Sin embargo, el precio de este contrato es libre y le 
permite al comercializador "premiar" al cliente, por ejemplo, por disminuir consumo durante una escasez. Además, la señora Juanita puede optar por otros contratos, pero es libre de volver al regulado.

En esencia, nuestro contrato regulado define que el derecho de propiedad sobre el suministro reside en la señora Juanita, pero le permite vender su derecho si le ofrecen algo que ella acepte. La idea es muy parecida a la solución que existe en los Estados Unidos para la sobreventa de pasajes aéreos. El pasaje le da derecho al pasajero a un asiento en el vuelo, y la compañía no lo puede dejar en tierra arbitrariamente. Pero la compañía puede premiar a un pasajero que voluntariamente decide renunciar al asiento. Es evidente que este mecanismo logra mejores resultados que la alternativa: un regulador que calcule el costo promedio de quedarse sin asiento (el costo de falla) y que compense al pasajero que aleatoriamente se quede en tierra (el racionamiento parejo).

Evidentemente, las compañías aéreas rematan al mejor postor el premio; pero el resultado es que se bajan del avión aquellos pasajeros cuyo costo de esperar es menor, y éstos siempre ganan. En el caso que nos interesa aquí, los comercializadores identificarían mediante ofertas inteligentes a los usuarios dispuestos a disminuir su consumo habitual al menor costo. Una regla como esta permitirá que los comercializadores recorran la curva de demanda logrando que se dejen de consumir los KWh que se valoran menos.

\subsubsection{La necesidad de la regulación prudencial de comercializadores}

El problema. Tal como ocurre en todo mercado en que se venden contratos que quedan sujetos a contingencias diversas, en este podría ocurrir que los comercializadores prometan condiciones que luego no pueden cumplir. Por ejemplo, un comercializador podría ofrecer energía muy barata, con la intención de no seguir entregándola cuando haya escasez aunque, por supuesto, sin advertírselo al cliente.

En la mayoría de los mercados existen mecanismos que impiden que ocurra algo así. En último término, tal vez la mejor salvaguardia es que en la generalidad de los casos el cliente tiene todos los incentivos para cubrirse contra esta posibilidad, porque asume los costos de contratar con una empresa que en la eventualidad no cumplirá —en este caso la promesa de entregar energía- Sin embargo, una característica física de los sistemas eléctricos impide que los clientes que contratan asuman directamente los costos de contratar con un mal comercializador. 
En efecto, en un sistema eléctrico la inyección de una central afecta a los flujos de potencia en cada una de las líneas interconectadas. Así, es imposible enviar un electrón desde un generador determinado a un cliente determinado. Todos los electrones inyectados por una central se juntan en la red de transmisión con los de las restantes centrales y se distribuyen de acuerdo con leyes físicas según donde estén ubicados quienes consumen. Por eso, no es suficiente que un comercializador deje de cumplir con su contrato para que sus clientes dejen de recibir electricidad; estos clientes deben ser desconectados. De lo contrario, en una escasez las intenciones de retiro superarán a la energía disponible y el resultado serán cortes de suministro que afectan a todos los usuarios. En otras palabras, un comercializador irresponsable perjudica a todo el sistema.

La solución: regulación prudencial. La literatura sobre el sistema bancario enseña que cuando existe riesgo sistémico se justifica la regulación prudencial. En este caso el fin de la regulación prudencial es evitar que en escasez (o incluso durante la operación normal) haya comercializadores que sobrevendan contratos, en la expectativa de que se decrete racionamiento parejo y se socialice el déficit. De ahí la siguiente propuesta:

Propuesta 6: Introducir la regulación prudencial de comercializadores. Ésta consiste en: a) una exigencia de capital mínimo a cada comercializador; b) una exigencia de calce entre energía y potencia vendida según contrato y contratada a firme con generadores, contingencia por contingencia.

Se le debe exigir un aporte de capital a cada comercializador para respaldar las eventuales multas que deberá pagar si viola los requerimientos prudenciales. El arriesgar su capital debiera estimular su prudencia.

La exigencia de calce es indispensable para mitigar el riesgo sistémico. En concreto, si $c_{i}^{c}(t)$ es consumo contratado por el cliente $i$ del comercializador en la contingencia $t$, y $e_{j}(t)$ es el suministro máximo que el comercializador puede recibir del generador $j$ según contrato en la contingencia $t$, en cada momento y contingencia, para cada comercializador debe cumplirse que

$$
\sum_{i=1}^{n} c_{i}^{c}(t) \leq \sum_{j=1}^{m} e_{j}(t)
$$

Para vigilar el cumplimiento de esta regla, es conveniente lo siguiente: 
Propuesta 7: El regulador debe llevar una contabilidad centralizada de los contratos de cada comercializador.

Pero es claro que, además, debe monitorearse que se cumplan los contratos. Es decir, en cada contingencia, pero sobre todo durante una escasez, los retiros efectivos de los clientes del comercializador, llamémos$\operatorname{los} c_{i}(t)$, no deben exceder a los contratados, vale decir

$$
\sum_{i=1}^{n} c_{i}(t) \leq \sum_{j=1}^{m} e_{j}(t)
$$

Más aún, las reglas deben garantizar que el comercializador cumpla en tiempo real. Vale decir, si no tiene respaldo, sus clientes deben disminuir su consumo para cumplir con (4.1) y debe ser posible hacer cumplir físicamente este requerimiento.

Cada uno de estos requerimientos prudenciales debe respaldarse con multas apropiadas y procedimientos expeditos que obliguen a pagarlas (sin perjuicio de que, una vez pagadas, puedan apelarse). Por último, es conveniente que existan planes para contingencias: debe estar claro qué hará cada comercializador para cumplir con los requerimientos prudenciales, sobre todo durante una escasez.

Propuesta 8: Deben existir planes de contingencia para situaciones de escasez. El plan de contingencia debiera decir qué clientes deben ser restringidos durante una escasez, lo cual debiera desprenderse de los contratos.

\subsubsection{Reglas de operación del sistema}

Por último, es importante destacar que el fin del precio de nudo no implica liberalizar el mercado spot. En nuestra opinión, esta liberalización es inconveniente porque les permitiría a los generadores explotar poder de mercado. Arellano (2004) muestra que se pueden esperar aumentos apreciables de precio si se liberaliza el despacho y los precios de ese mercado se traspasan a los clientes. Por eso, nuestra última propuesta es:

Propuesta 9: Continuar con el despacho a costo marginal.

Existen algunos ajustes que seguramente habría que hacerles a las reglas de despacho, ya sea para mejorarlas o bien para evitar inconsistencias. Estos ajustes son necesarios, pero los dejamos para otro trabajo. 


\section{Algunas consecuencias de la liberalización}

\subsection{Liberalización, precios y competencia}

Una de las objeciones que se esgrimen todo el tiempo en contra de la liberalización es que los precios podrían aumentar. Por alguna razón, a muchos les parece que la competencia es un medio indirecto e incluso incierto de garantizar precios cercanos a los costos de oportunidad. En nuestra opinión, sin embargo, esta creencia, no se justifica. A continuación discutimos por qué.

¿Multicarrier o AFP? En mercados liberalizados, tales como el multicarrier, la competencia en precios ha resultado ser intensa y las caídas de precio que siguieron a la desregulación fueron apreciables. Sin embargo, en algunos mercados, como el de las AFP, la competencia en precios no ha funcionado ${ }^{30}$. ¿Cuán intensa sería la competencia en precios en la comercialización de electricidad y qué asegura que la liberalización no terminará como las AFP?

Para comenzar, nótese que la comercialización consiste en vender contratos, medir y facturar, tareas que no parecen beneficiarse con economías de escala tales que impidan la coexistencia de varias empresas. El principal costo de entrada será la exigencia de capital (que ya justificamos por razones prudenciales) y es muy probable que este requisito determine la escala de los comercializadores.

Sin embargo, la ausencia de economías de escala no es suficiente para que la competencia en precios sea intensa. El diseño de algunas reglas no sólo es importante, sino determinante.

Para comenzar, y como ya se dijo, es indispensable separar el cobro por distribución eléctrica de los cobros por energía o potencia. Cada usuario debiera conocer su peaje de distribución antes de contratar con un comercializador. De lo contrario, el distribuidor siempre puede fijar el peaje para explotar su poder de mercado.

Segundo, para que la competencia en precios sea intensa es necesario que los costos de cambio de un comercializador a otro sean bajos. Hay una serie de detalles que pueden parecer irrelevantes a primera vista, pero que terminan siendo determinantes. Por ejemplo, los medidores deben ser compatibles y de propiedad de los usuarios. Asimismo, para cambiarse de comercializador debiera bastar un llamado telefónico o llenar un formulario en una página web.

${ }^{30}$ Véanse Valdés (2004) y Valdés y Marinovic (2004). 
Al mismo tiempo, se debería evitar el error de introducir reglas que en apariencia limitan el ejercicio del poder de mercado, pero en realidad lo favorecen. Una de ellas es exigirle a cada comercializador que les cobre lo mismo a todos sus clientes; cuando así se hace, como ocurre con las AFP, la competencia en precios es tenue. Cuando, por el contrario, no existe la obligación de cobrarles lo mismo a todos los clientes, la competencia en precios es intensa ${ }^{31}$.

Esfuerzo de ventas. En algunos mercados la competencia requiere esfuerzos de venta y el costo de contactar a un cliente es independiente de su volumen de compras. Para los clientes que demandan entre $5 \mathrm{KW}$ y 500 KW - v. gr., supermercados, centros comerciales, hoteles, industrias medianas - y para el millón de clientes que consumen en promedio $200 \mathrm{KWh}$ al mes —oficinas, pequeños comercios y casas de ingresos medios y altos- seguramente se justifican los esfuerzos de venta. Pero es posible que el volumen de las compras de clientes residenciales muy pequeños sea insuficiente. Si así fuera, el problema tiene solución si el suministro de grupos grandes de consumidores pequeños se licita, siguiendo líneas similares a lo que propone Valdés (2004) para las AFP.

\subsection{Tres razones de por qué la electricidad no debiera aumentar de precio}

\section{Diferenciación de la tarifa de energía, potencia y distribución para} clientes residenciales. Uno de los principales defectos de la tarificación de energía residencial (la tarifa BT1) es que combina en un precio monómico el cobro de la energía, de la potencia y de las instalaciones de subtransmisión y distribución ${ }^{32}$. De esta forma, el cobro de potencia, subtransmisión y distribución se prorratea entre los KWh de energía consumidos por el hogar a lo largo de todo el año. Si bien la tarifa se calcula para que el pago total sea lo más parecido a la suma del costo de energía y del resto de los cargos,

${ }^{31} \mathrm{Si}$ una empresa disminuye unilateralmente su precio, el cambio de las utilidades es

$$
\Delta I-\Delta C=\left(p-c_{\mathrm{mg}}\right) \cdot \Delta q+q \cdot \Delta p,
$$

donde " $\Delta$ " denota cambio, $I$ ingresos, $C$ costos, $p$ precio, $q$, cantidad y $c_{\mathrm{mg}}$ costo marginal. Nótese que el primer término, $\left(p-c_{\mathrm{mg}}\right) \cdot \Delta q$, es el beneficio de bajar los precios —el margen prebaja multiplicado por las ventas adicionales_- El costo de bajar el precio es $q \cdot \Delta p-\operatorname{los}$ menores ingresos por vender a precio menor lo que ya se vendía antes de bajar el precio-.

Cuando las empresas pueden bajar selectivamente sus precios, el costo de hacerlo es menor. Se puede demostrar que, entonces, el precio de equilibrio es menor. Por el contrario, la prohibición de cobrar precios distintos, lejos de intensificar la competencia, la atenúa.

${ }^{32}$ En el Apéndice D se muestra la fórmula de cálculo de la tarifa BT1 y se explica la tarificación de la distribución. 
la tarifa monómica hace que se consuma muy poca energía y causa una distorsión.

El Gráfico $\mathrm{N}^{\circ} 8$ ilustra el problema. El prorrateo del VAD y de la potencia aumenta la tarifa de energía desde $p_{N}$, el precio de nudo de la energía hasta $p_{B}$, y la tarifa BT1. Por ejemplo, en abril de 2004 el precio de nudo de la energía era alrededor de US\$ $0,04 / \mathrm{KWh}$ mientras que la tarifa BT1 era alrededor de US\$ 0,09/KWh. Es decir, apenas alrededor del $45 \%$ de la tarifa paga el consumo de energía, el resto paga la potencia (25\%) y el VAD $(30 \%)^{33}$. La distribuidora compra energía a precio de nudo y la potencia necesaria para servir al cliente. Si la tarifa está bien calculada, el excedente que obtiene la distribuidora cuando vende energía —el rectángulo $p_{N} A C p_{B}$ - es igual al costo de la potencia y de las instalaciones necesarias para servir al cliente. Sin embargo, el precio de la energía es muy alto y por ello se pierde el triángulo $\triangle S \equiv A B C$.

¿De qué tamaño es el triángulo $\Delta S$ ? Benavente et al. (2004) estimaron que la elasticidad de largo plazo de la demanda por electricidad era $-0,39$. Tal elasticidad indica que si el precio de la energía cayera permanentemente desde \$0,09/KWh hasta \$0,04/KWh, la cantidad demandada

GRÁFICO N ${ }^{\circ} 8: \quad$ EL COSTO SOCIAL DE LA TARIFA BT1

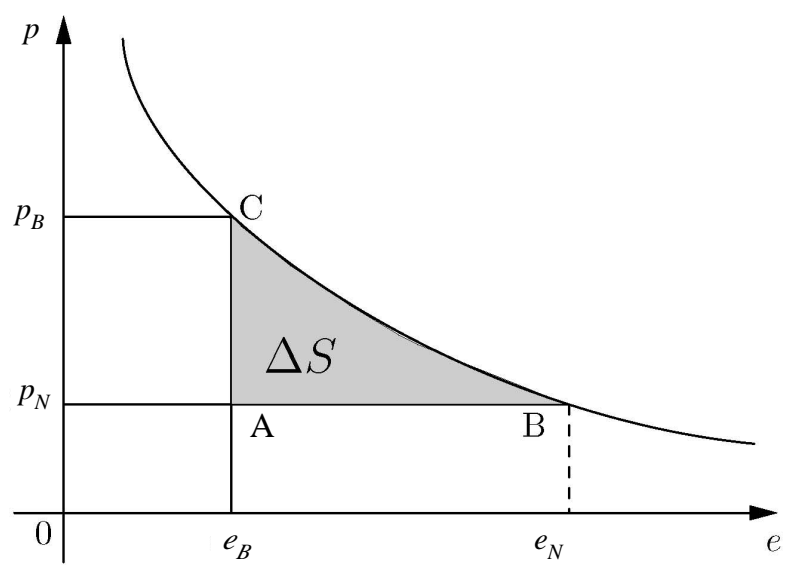

${ }^{33}$ Este valor incluye recargos por transformación y distancia en subtransmisión. 
aumentaría en $37 \%$ y el triángulo $\Delta S$ equivaldría al $8,75 \%$ del gasto total por energía, $p_{B} \cdot e_{B}$; vale decir, $\Delta S /\left(p_{B} \cdot e_{B}\right) \simeq 8,75 \%$.

Es razonable pensar que los comercializadores cobrarían por separado la potencia y la energía, y la competencia los obligaría a cobrar algo cercano al precio promedio de la energía ${ }^{34}$. Si se considera que en 2004 existían alrededor de 4,5 millones de clientes acogidos a la tarifa BT1 que consumían alrededor de $7.700 \mathrm{GWh}$ al año, se llega a que la ganancia de bienestar es del orden de los US\$ 58 millones por año. Si además se recuerda que la hipotética pérdida del gas significaría un aumento de tarifas del orden del $13 \%$, se obtiene que la sola eliminación de esta distorsión compensa más de la mitad —es como si a los consumidores se les regalara un cheque equivalente al triángulo- ${ }^{35}$.

Curva de carga más plana: potencia. Una vez que se liberaliza, se abre espacio para que los contratos entre consumidores y comercializadores eliminen ineficiencias. Una de ellas es que los clientes residenciales que pagan la tarifa BT1 consumen demasiada potencia en la hora de demanda máxima, porque no se les cobra directamente. Por ejemplo, en julio da lo mismo planchar a las 7 PM (la hora punta) o a las 9 AM, sólo porque la tarifa no distingue horario. La consecuencia es que el factor de planta de las centrales que abastecen la demanda es más bajo de lo que sería si el consumo de los clientes fuese más parejo —es decir, una fracción mayor de la capacidad instalada se ocupa por menos horas, lo que finalmente aumenta el costo de suministro- ${ }^{36}$.

¿De qué monto es la pérdida social debida a esta ineficiencia? Es difícil saberlo, porque no existen estimaciones de la demanda residencial

${ }^{34}$ Existen dos maneras de cobrar por separado la potencia y la energía. Una es mediante un medidor que mida el consumo horario; la otra es que al cliente se le cobre un cargo fijo proporcional al tamaño de su conexión. Según fuentes que consultamos, los medidores que permiten monitorear el consumo horario cuestan alrededor de US\$ 60 (al por menor).

${ }^{35}$ Una posible objeción a nuestro cálculo es que no considera que el aumento de la demanda por energía que ocurriría (37,1\% si la tarifa de energía cae desde US\$ 0,09/KWh hasta US\$ 0,04/KWh) requeriría aumentar la capacidad instalada de generación. Sin embargo, el precio promedio de la energía cubre la capacidad adicional inframarginal (vale decir, aquella que no está ahí para dar la punta). Ciertamente, suponemos constante la demanda por potencia; pero éste es un supuesto conservador, puesto que si se tarifica por separado, seguramente habrá incentivos para disminuirla.

${ }^{36} \mathrm{El}$ factor de planta es igual a la razón

$$
\frac{\text { Energía total producida durante el año }}{\text { (potencia de la central }) \times 8.760 \text { horas }},
$$

(el año tiene 8.760 horas). 
CUADRO $\mathrm{N}^{\circ}$ 4: $\quad$ COSTO DE ABASTECIMIENTO Y FACTOR DE CARGA

(1)

Factor de carga ${ }^{\mathrm{i}}$
(2)

Costo de expansión

(en US\$ por MWh) ${ }^{\mathrm{ii}}$

\begin{tabular}{ccc}
\hline $\mathbf{7 0 \%}$ & $\mathbf{4 8 , 2 6}$ & Cliente residencial \\
$71 \%$ & 47,83 & \\
$72 \%$ & 47,41 & \\
$73 \%$ & 47,00 & \\
$\mathbf{7 4 \%}$ & $\mathbf{4 6 , 6 0}$ & \\
$75 \%$ & 46,21 & \\
$76 \%$ & 45,83 & \\
$77 \%$ & 45,46 & \\
$78 \%$ & 45,11 & \\
$79 \%$ & 44,76 & \\
$80 \%$ & 44,41 & \\
$81 \%$ & 44,08 & \\
$82 \%$ & 43,76 & \\
$83 \%$ & 43,44 & \\
$\mathbf{8 4 \%}$ & $\mathbf{4 3 , 1 3}$ & \\
$85 \%$ & 42,83 & \\
$86 \%$ ii & 42,54 & \\
$87 \%$ & 42,25 & \\
$88 \%$ & 41,97 & \\
$89 \%$ & 41,69 & \\
$90 \%$ & 41,42 & \\
\hline
\end{tabular}

Notas: (i) El factor de carga es la razón entre demanda media de potencia y la demanda máxima de potencia. (ii) El costo de expansión es el precio monómico de la energía que sería necesario para rentar a una planta de carbón suponiendo un factor de planta igual al de carga.

Fuente: El factor de carga del sistema se obtuvo del informe de precio de nudo de la CNE de abril de 2004. Las estimaciones del factor de carga de clientes libres y residenciales fueron hechas por los autores.

por potencia. Pero el Cuadro $\mathrm{N}^{\circ} 4$, que muestra el precio monómico necesario para rentar a una planta de carbón a cada factor de planta, sugiere que el costo de abastecimiento podría disminuir bastante si el consumo residencial fuese más parejo. En efecto, se aprecia que si el factor de planta de un cliente residencial es $70 \%$, se requiere un precio monómico de US\$ 48,26/ MWh para rentar una central a carbón. Si los clientes residenciales se comportasen como el promedio del sistema, el costo sería US\$ 46,6/MWh, casi US\$ 2/MWh menos. Y si se llegase a algo parecido al factor de carga de un cliente libre promedio, el costo sería apreciablemente menor, 
US\$ 43,13/MWh. Por supuesto, es una cuestión empírica si acaso tales disminuciones del costo compensan las incomodidades de consumir menos en la hora punta. Pero el Cuadro $\mathrm{N}^{\circ} 4$ indica que los incentivos son apreciables.

Por supuesto, en la actualidad la tarifa BT1 contiene un cobro indirecto de potencia, la tarifa de invierno. Así, los clientes residenciales que sobrepasan el límite de invierno pagan considerablemente más por KWh consumido más allá del límite. Pero, en realidad, este cobro exacerba el problema: el sobrecosto tampoco distingue entre horas y a esta distorsión se le agrega que en invierno los hogares afectados consumen menos energía aún que el triángulo $\Delta S$ del Gráfico $\mathrm{N}^{\circ} 8$.

Curva de carga más plana: energía. Un beneficio adicional de la liberalización es que, seguramente, el precio de la energía y el consumo seguirían más de cerca al costo de oportunidad corriente de la energía —el precio sería más alto en años secos y más bajo en años húmedos-. Montero y Rudnick (2001) estiman que, de ser flexibles los precios, la capacidad instalada necesaria para servir el consumo caería entre 20 y $30 \%{ }^{37}$. La competencia debiera traspasarle los ahorros a los consumidores en forma de menores precios, porque en un mercado competitivo existen incentivos para que las empresas detecten consumidores que están dispuestos a consumir cantidades variables, dependiendo de las condiciones de abastecimiento.

\subsection{Una escasez debiera costar mucho menos}

Una de las principales virtudes de la liberalización es que una escasez costaría bastante menos. La razón es que los comercializadores ganarían plata identificando las disminuciones de consumo baratas, vale decir, aquellos KWh que los usuarios valoran menos en el margen. Si así ocurriera, ¿cuánto menos costaría una restricción?

Una restricción eficiente de consumo consiste en que la igualdad entre energía disponible y consumida durante una escasez de agua u otro combustible se logra dejando de consumir aquellos KWh que valen menos. Una manera de hacerlo es dejar que el precio de la energía aumente hasta que la cantidad consumida iguale a la disponible. Otra es que el costo de oportunidad de los KWh marginales consumidos aumente. En ambos casos,

\footnotetext{
${ }^{37}$ Reportamos los resultados que se obtienen suponiendo elasticidades de la demanda en el rango de la estimada por Benavente et al. (2004).
} 


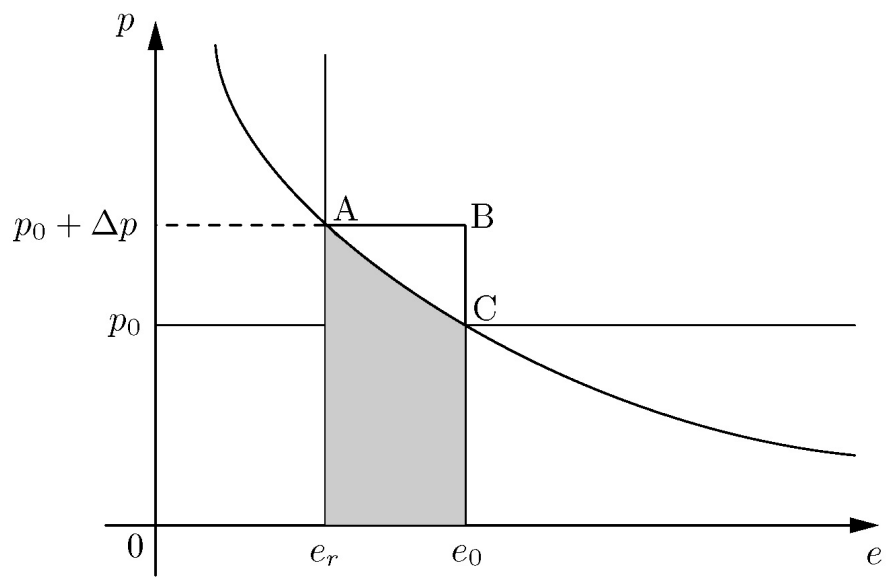

el costo bruto de la restricción es igual al área que está debajo de la curva de demanda entre el consumo normal y el consumo restringido.

Así, supongamos que, como en el Gráfico $\mathrm{N}^{\circ}$, el consumo sin restricción es $e_{0}$, y la restricción obliga a disminuirlo a $e_{r}$. El costo bruto de una restricción eficiente es el área sombreada $e_{r} e_{0} C A$. Por contraste, si, como ahora, la restricción se administra racionando por parejo, se estima que cada KWh restringido cuesta US\$ 0,22/KWh. El costo bruto de una restricción es, entonces, $\left(e_{0}-e_{r}\right) \times 22,1$. Para obtener el costo neto de la restricción se le debe restar al costo bruto lo que hubiera costado producir los KWh no suministrados; este costo es cero si la restricción ocurre por sequía.

Si se conociera el aumento de precio necesario para disminuir el consumo desde $e_{0}$ hasta $e_{r}-\Delta p$ en el Gráfico $\mathrm{N}^{\circ} 9-$, se podría aproximar el costo de una restricción eficiente con

$$
\left(e_{0}-e_{r}\right) \times(p+\Delta p)
$$

el rectángulo $e_{r} e_{0} B A$ en el Gráfico $\mathrm{N}^{\circ}$ 9. Al mismo tiempo, el costo por KWh de una restricción eficiente no es mayor que $p+\Delta p$. En el Apéndice $\mathrm{C}$ mostramos cómo se puede utilizar la estimación de la demanda residencial por energía de Benavente et al. (2004) para estimar $\Delta p$. El 
CUADRO $\mathrm{N}^{\circ}$ 5: $\quad$ CAÍDA TOTAL DE CONSUMO SI EL COSTO AUMENTA EN EL MARGEN

(a) Con tarifa monómica

(tarifa base: 9 centavos/KWh)

\begin{tabular}{l|cccccccc} 
Meses & 10 & 11 & 12 & 13 & 14 & 15 & 16 & 17 \\
\hline 1 & & & & & & & & \\
2 & $0,58 \%$ & $1,10 \%$ & $1,57 \%$ & $2,00 \%$ & $2,40 \%$ & $2,77 \%$ & $3,11 \%$ & $3,43 \%$ \\
3 & $0,83 \%$ & $1,28 \%$ & $1,83 \%$ & $2,33 \%$ & $2,79 \%$ & $3,21 \%$ & $3,61 \%$ & $3,98 \%$ \\
4 & $0,97 \%$ & $1,82 \%$ & $2,24 \%$ & $2,85 \%$ & $3,41 \%$ & $3,93 \%$ & $4,42 \%$ & $4,87 \%$ \\
5 & $1,10 \%$ & $2,07 \%$ & $2,95 \%$ & $3,30 \%$ & $3,95 \%$ & $4,55 \%$ & $5,11 \%$ & $5,63 \%$ \\
6 & $1,22 \%$ & $2,30 \%$ & $3,28 \%$ & $4,16 \%$ & $4,97 \%$ & $5,16 \%$ & $5,79 \%$ & $6,37 \%$ \\
7 & $1,34 \%$ & $2,52 \%$ & $3,59 \%$ & $4,55 \%$ & $5,44 \%$ & $6,72 \%$ & $6,42 \%$ & $7,06 \%$ \\
8 & $1,45 \%$ & $2,73 \%$ & $3,88 \%$ & $4,92 \%$ & $5,87 \%$ & $6,75 \%$ & $7,01 \%$ & $7,71 \%$ \\
9 & $1,56 \%$ & $2,92 \%$ & $4,15 \%$ & $5,27 \%$ & $6,29 \%$ & $7,22 \%$ & $8,09 \%$ & $8,32 \%$ \\
10 & $1,65 \%$ & $3,11 \%$ & $4,41 \%$ & $5,59 \%$ & $6,67 \%$ & $7,66 \%$ & $8,58 \%$ & $9,43 \%$
\end{tabular}

(b) Separando energía y potencia

(tarifa base: 4 centavos/KWh)

\begin{tabular}{l|cccccccc} 
Meses & 4,5 & 5 & 5,5 & 6 & 6,5 & 7 & 7,5 & 8 \\
\hline 1 & $0,64 \%$ & $1,21 \%$ & $1,73 \%$ & $2,20 \%$ & $2,62 \%$ & $3,02 \%$ & $3,38 \%$ & $3,73 \%$ \\
2 & $0,75 \%$ & $1,41 \%$ & $2,01 \%$ & $2,55 \%$ & $3,05 \%$ & $3,51 \%$ & $3,93 \%$ & $4,32 \%$ \\
3 & $0,92 \%$ & $1,73 \%$ & $2,46 \%$ & $3,13 \%$ & $3,73 \%$ & $4,29 \%$ & $4,80 \%$ & $5,28 \%$ \\
4 & $1,06 \%$ & $2,01 \%$ & $2,85 \%$ & $3,62 \%$ & $4,32 \%$ & $4,96 \%$ & $5,55 \%$ & $6,10 \%$ \\
5 & $1,21 \%$ & $2,28 \%$ & $3,24 \%$ & $4,11 \%$ & $4,90 \%$ & $5,62 \%$ & $6,29 \%$ & $6,91 \%$ \\
6 & $1,35 \%$ & $2,54 \%$ & $3,60 \%$ & $4,56 \%$ & $5,43 \%$ & $6,23 \%$ & $6,97 \%$ & $7,65 \%$ \\
7 & $1,48 \%$ & $2,78 \%$ & $3,94 \%$ & $4,99 \%$ & $5,94 \%$ & $6,81 \%$ & $7,61 \%$ & $8,36 \%$ \\
8 & $1,60 \%$ & $3,01 \%$ & $4,26 \%$ & $5,39 \%$ & $6,41 \%$ & $7,35 \%$ & $8,21 \%$ & $9,01 \%$ \\
9 & $1,71 \%$ & $3,22 \%$ & $4,56 \%$ & $5,77 \%$ & $6,86 \%$ & $7,86 \%$ & $8,78 \%$ & $9,63 \%$ \\
10 & $1,82 \%$ & $3,42 \%$ & $4,85 \%$ & $6,12 \%$ & $7,28 \%$ & $8,34 \%$ & $9,31 \%$ & $10,21 \%$
\end{tabular}

Fuente: Se utilizó la demanda estimada por Benavente et al. (2004), según lo explicado en el Apéndice C.

resultado de esa estimación es el Cuadro $\mathrm{N}^{\circ} 5$, el que muestra en cuánto caería el consumo de energía si el precio marginal aumentase.

En el panel $a$ el punto de partida es la tarifa residencial BT1 que actualmente cobra Chilectra por KWh (alrededor de US\$ 0,09/KWh). Hacia la derecha, el costo de cada KWh en el margen aumenta sucesivamente desde US\$ 0,09/KWh hasta 0,10, 0,11 y hasta US\$ 0,17/KWh. Hacia abajo se muestra el número de meses durante los cuales se mantiene el aumento del costo. Así, por ejemplo, la celda $(5,12)$ indica que si aumentase desde 
US \$ 9/KWh hasta US\$ 0,12/KWh, y ese aumento se mantuviese por cinco meses, el consumo de energía sería 2,95\% menos durante todo el período. El panel $b$ repite el ejercicio, esta vez tomando como punto de partida un costo de la energía de US\$ 0,04/KWh.

Un buen punto de referencia es la crisis eléctrica de 1998 y 1999. Entre noviembre de 1998 y junio de 1999 se racionaron 450 GWh (véase Díaz et al., 2000), mientras que en ese entonces se consumían alrededor de $2.000 \mathrm{GWh}$ al mes. Por otro lado, ya en septiembre de 1998 se sabía que el año sería seco. ¿En cuánto debería haber aumentado el costo en el margen para que se hubieran consumido $450 \mathrm{GWh}$ menos entre octubre de 1998 y junio de 1999 ?

Los $450 \mathrm{GWh}$ equivalen al 2,5\% del consumo de energía total durante nueve meses. El panel $a$ indica que para lograr que el consumo residencial caiga en $2,5 \%$ se requiere que el precio aumente desde US $\$ 0,09 / \mathrm{KWh}$ a poco menos de US\$ $0,11 / \mathrm{KWh}$. Por otro lado, el costo del racionamiento parejo es US\$ $0,22 / \mathrm{KWh}$. Vale decir, el costo de racionar por parejo es más del doble de lo que habitualmente se paga por la energía.

Pero vimos que una liberalización probablemente terminaría con la tarifa residencial monómica. Si la tarifa por energía cayera a US\$ 0,04/ KWh, una restricción eficiente costaría aún menos —en el margen, los KWh restringidos valen menos aún-. El panel $b$ muestra que para disminuir el consumo de nueve meses en $2,5 \%$ se necesita aumentar desde US\$ $0,04 / \mathrm{KWh}$ a menos de US\$ $0,05 / \mathrm{KWh}$. Vale decir, jel costo de racionar por parejo es más de cuatro veces mayor!

Hecho 8. Una restricción como la ocurrida entre noviembre de 1998 y junio de 1999 (aproximadamente 2,5\% del consumo total de energía) se podría haber materializado a un costo apreciablemente menor.

Hay una manera alternativa de apreciar el absurdo que impone el actual racionamiento parejo: calcular qué sacrificio de consumo hubiera sido necesario para superar la crisis de 1998-1999. Como ya se dijo, entre noviembre de 1998 y junio de 1999 se racionaron 450 GWh de energía (aunque a lo menos desde septiembre de 1998 se sabía que habría racionamiento). Adicionalmente, la máxima restricción impuesta en un momento dado fue de $641 \mathrm{MW}$.

Ahora bien, existen hoy en día alrededor de cuatro millones de clientes residenciales que pagan la tarifa BT1. Un simple cálculo muestra que si 
se cuenta con nueve meses para disminuir el consumo en 450 GWh (entre septiembre y junio), basta con que cada uno reduzca su consumo diario en el equivalente un poco más de una ampolleta de $40 \mathrm{~W}$ por diez horas ${ }^{38}$. Vale decir, la crisis eléctrica de 1998-1999 se habría superado sin cortes de suministro si cada cliente residencial hubiese apagado el equivalente a una ampolleta de $40 \mathrm{~W}$ por diez horas cada día durante nueve meses. Al mismo tiempo, la máxima restricción impuesta en un momento del racionamiento (los $641 \mathrm{MW}$ ) se habría superado si cada cliente hubiese reducido su consumo en $160,25 \mathrm{~W}^{39}$.

Por supuesto, en muchos casos apagar una ampolleta de $40 \mathrm{~W}$ no es poco. Un buen número de usuarios consume menos de $50 \mathrm{KWh}$ al mes y para ellos eso significa disminuir el consumo en un cuarto. Pero, por otro lado, este cálculo no incluye a todos los restantes clientes, responsables del $70 \%$ del consumo total. El punto que queremos hacer notar es que las reducciones de consumo necesarias para que sea innecesario cortar el suministro durante una escasez son perfectamente alcanzables.

\section{Conclusión}

Iniciamos este trabajo argumentando que el debate sobre gas y electricidad se ha enfocado mal. La respuesta apropiada a la crisis del gas no es asegurar el abastecimiento de este u otro combustible, sino corregir los defectos del sistema de precios actual debido a los cuales una escasez de gas o de agua deviene en una crisis eléctrica. Hay mucho en juego porque la pérdida del gas significaría un gran perjuicio para Chile, del orden de los US\$ 350 millones anuales. Esto es equivalente a la mitad de lo que ganó el país por firmar los acuerdos comerciales con Estados Unidos y la Unión Europea. Por lo mismo, salvar el gas natural sería un muy buen negocio para Chile.

Existen, en principio, al menos dos maneras de hacerse cargo de los problemas que causa la volatilidad de la disponibilidad de gas natural. Una

${ }^{38}$ El cálculo exacto es:

$$
\frac{450 \mathrm{GWh}}{4.000 .000 \times 10 \mathrm{~h} \times 270 \text { días }}=41,66 \mathrm{~W} .
$$

${ }^{39}$ El cálculo exacto es:

$$
\frac{641 \mathrm{MW}}{4.000 .000}=160,25 \mathrm{~W} \text {. }
$$


es ajustar el modelo actual para incorporarle medidas tales como incluir la probabilidad de una "sequía de gas" en el cálculo de la potencia firme. El principal defecto de esta solución es que es ad hoc y muy imperfecta porque no se hace cargo del problema de fondo. ¿Cuál es ese problema? El punto central de este trabajo es que en Chile los episodios de escasez de energía son inevitables, sea porque ocurre una sequía, falla una central o, como hemos aprendido recientemente, porque los argentinos interrumpen discrecionalmente el suministro de gas natural. Los episodios de escasez de energía ocurren porque la disponibilidad de algunos combustibles que se ocupan para generar electricidad es volátil. Sin embargo, una escasez no necesariamente deviene en crisis. Las crisis son consecuencia de que el sistema de precios y contratos a usuarios finales que existe actualmente es rígido: no distribuye claramente los riesgos de insumos de oferta volátil (agua y gas natural); y es inflexible para acomodar eventos de escasez de insumos.

La segunda manera de hacerse cargo de los problemas que causan los insumos de disponibilidad volátil es liberalizar la comercialización de energía, eliminando con ello el precio de nudo. Hemos argumentado que la liberalización de la comercialización es triplemente conveniente: salva el gas natural, evita que una escasez de agua, gas natural o cualquier otro combustible de disponibilidad volátil que se introduzca en el futuro (v. gr., viento) devengue en crisis. Y, por último, la competencia traería una muy necesaria modernización del sistema de comercialización y precios a usuarios, eliminando una serie de costosas distorsiones que, es probable, incluso compensarían la eventual pérdida del gas natural.

¿Es posible hacer esta reforma? Dejemos de lado la siempre invocada pero nunca precisada factibilidad política. Es indudable que nuestra propuesta aún es incompleta, porque no explica cómo resolver una serie de detalles prácticos, algunos de los cuales pueden hacer la diferencia entre el éxito o el fracaso. Pero al mismo tiempo hemos mostrado que los beneficios brutos del proyecto son apreciables — del orden de varios cientos de millones de dólares anuales-. Con esto, esperamos haber convencido al lector que vale la pena destinar un par de miles de dólares y de esfuerzo del gobierno para estudiar esta reforma seriamente y con premura. 


\section{APÉNDICE}

\section{A. Precios y la asignación de la energía durante un déficit}

Como vimos, cuando ocurre un déficit el precio spot debiera ser igual al costo de falla y, si el regulador dicta un decreto de racionamiento, los generadores pagarán a los usuarios regulados la diferencia entre el costo de falla y el precio de nudo por cada KWh no servido. En ese caso, todos los agentes en el mercado enfrentan el costo de oportunidad de la energía en el margen (el costo de falla) y en equilibrio no ocurren cortes. Es posible demostrar que la asignación de la energía que se obtiene es la óptima social (véase Díaz et al., 2001). A continuación detallamos los incentivos que enfrentan los agentes en cada uno de los mercados.

Operando en su propio interés, tanto los generadores con déficit como los excedentarios tienen incentivos para aumentar la cantidad ofrecida de energía y reducir el exceso de demanda. En efecto, para disminuir sus compras en el mercado spot y los montos compensados a clientes regulados, los generadores con déficit agregarán turbinas mientras su costo de operación sea menor que el costo de falla; comprarán a autoproductores (tales como las grandes empresas mineras que mantienen sus propias unidades de reserva) en tanto éstos estén dispuestos a vender energía a menos que el costo de falla; y negociarán disminuciones voluntarias de consumo con clientes libres para quienes el valor de la energía sea menor que el costo de falla. Por su parte, los generadores excedentarios también tienen incentivos para vender en el mercado spot a costo de falla.

En el mercado regulado, la menor disponibilidad de agua embalsada en el lago Laja se traducirá en un aumento de su costo alternativo y, por consiguiente, del precio de nudo. Sin embargo, este efecto no es muy grande porque, como ya se dijo, el precio de nudo es un promedio ponderado de los costos marginales esperados para los siguientes cuatro años, valor que es muy poco sensible a una sequía. Pero el efecto de las compensaciones debería ser más importante. En vista de que la compensación es igual a la diferencia entre el costo de falla y el precio de nudo, aquellos consumidores que valoran un KWh de energía en menos que el costo de falla disminuirán voluntariamente su consumo porque preferirán ser compensados. Así, la compensación por reducción de consumo ordena a los clientes regulados de mayor a menor disposición a pagar y se dejan de consumir aquellos KWh que se valoran en menos que el costo de falla.

De manera similar, en el mercado libre los generadores que no puedan cumplir con sus contratos deberán evaluar en qué medida les con- 
viene compensar a sus clientes, negociar para que disminuyan su consumo o, incluso, instalarles equipos de emergencia. Y, como se dijo, los generadores con superávit también tienen incentivos para negociar reducciones de consumo por aquellos KWh que valgan menos que el costo de falla. Tal como en el mercado regulado, estas negociaciones deberían ordenar a los clientes libres según su valoración, de modo que finalmente se consumirán únicamente aquellos KWh valorados a más que el costo de falla.

En resumen, aun en sequías extremas, si los precios (spot, nudo y libre), el costo de falla y las compensaciones son calculados correctamente, el mercado competitivo conducirá a un equilibrio sin cortes de energía.

\section{B. Cálculo de la distorsión por tarificación monómica de clientes residenciales}

En este apéndice detallamos las fórmulas de cálculo del monto de la distorsión que impone la tarificación monómica de la energía de clientes residenciales que pagan la tarifa BT1.

Si la demanda por energía de un hogar es de elasticidad constante, se puede escribir como

$$
e=A \cdot p^{\eta}
$$

Donde $e$ es la energía demandada en KWh, $p$ es el precio de la energía por KWh, $\eta$ es la elasticidad de la demanda y $A$ incluye todos los restantes determinantes de la demanda por energía, los que se suponen constantes.

Supongamos ahora que la tarifa monómica BT1, llamémosla $p_{B}$, se sustituye por una que separa la energía de la potencia. A consecuencia de este cambio la tarifa de energía cae a $p_{N}$, el precio de nudo de la energía ajustado por pérdidas. Suponiendo que $\left(p_{B}-p_{N}\right) e_{0}$ remunera la potencia demandada por el cliente que pagaba la tarifa BT1, que el cliente continuará pagando por separado, el cambio del excedente del consumidor es

$$
\Delta S=A \int_{p N}^{p B} p^{\eta} d p-\left(p_{B}-p_{N}\right) e_{B}=\frac{A}{1+\eta} \cdot\left(p_{B}^{1+\eta}-p_{N}^{1+\eta}\right)-\left(p_{B}-p_{N}\right) e_{B},
$$

donde $\Delta S$ denota el cambio del excedente. Notando que $\mathrm{A} \equiv e_{B} \cdot p_{B}{ }^{-\eta}$, esta expresión se puede volver a escribir como 


$$
\left[\frac{p_{B}^{-\eta}}{1+n} \cdot\left(p_{B}^{1+\eta}-p_{N}^{1+\eta}\right)-\left(p_{B}-p_{N}\right)\right] \times e_{B}
$$

Si consideramos que la cuenta inicial que paga el consumidor es $p_{B} \cdot e_{B}$, el cambio del excedente como proporción de la cuenta inicial es

$$
\frac{1}{1+\eta} \times\left[1-\left(\frac{p_{N}}{p_{B}}\right)^{1+\eta}\right]-\frac{p_{B}-p_{N}}{p_{B}}
$$

En el caso del SIC, la tarifa monómica promedio es alrededor de US\$ 0,09/KWh. El precio de nudo de la energía ajustado por pérdidas es alrededor de US\$ 0,04/KWh. Finalmente, según Benavente et al. (2004), la elasticidad de largo plazo de la demanda residencial es $-0,39$, el cambio de excedente de un consumidor tal que $e_{0}=1 \mathrm{GWh}$ es:

$\Delta S=\left[\frac{0,09^{0,39}}{0,61} \cdot\left(0,09^{0,61}-0,04^{0,61}\right)-0,05\right] \times 1.000 .000 \approx \$ \mathrm{US} 7.560 / \mathrm{GWh}(\mathrm{B} .1)$

Como porcentaje de la cuenta inicial, la ganancia de excedente es igual a

$$
\frac{\Delta S}{p_{B} \cdot e_{B}}=\left\{\frac{1}{0,61} \times\left[1-\left(\frac{0,04}{0,09}\right)^{0,61}\right]-\frac{0,05}{0,09}\right\} \approx 0,084 \equiv 8,4 \% .
$$

El tamaño del triángulo se calcula notando que, según fuentes de la industria, el consumo de clientes BT1 en 2000 alcanzó a 523,25 GWh mensuales. Suponiendo que entre 2000 y 2003 el consumo BT1 creció a la misma tasa que las ventas en el SIC (2001: 5,7\%; 2002: 4,1\%; 2003: 5,8\%) y que en 2004 las ventas crecerán 5\%, se llega a un consumo anual de 7.675 GWh en 2004. Finalmente, usando la expresión (4.1), se obtiene que

$7.560 \$ \mathrm{US} / \mathrm{GWh} \times 7.675 \mathrm{GWh} \simeq \mathrm{US} \$ 58$ millones. 


\section{Cálculo del costo de una restricción eficiente del consumo ante escasez}

Una restricción eficiente de consumo consiste en que la igualdad entre energía disponible y consumida durante una escasez de agua u otro combustible se logra dejando de consumir aquellos KWh que valen menos. Una manera de hacerlo es dejar que el precio de la energía aumente hasta que la cantidad consumida iguale a la disponible. Otra es que el costo de oportunidad de los KWh marginales consumidos aumente. En ambos casos, el costo bruto de la restricción es igual al área debajo de la curva de demanda entre el consumo normal y el consumo restringido. El costo neto de la restricción eficiente le resta al costo bruto lo que hubiera costado producir los KWh no disponibles. Este costo es cero si la restricción ocurre por una sequía.

El cálculo del menor costo de una restricción que presentamos en el texto se obtuvo de la siguiente manera. Benavente et al. (2004) estiman que la demanda residencial mensual por energía es

$$
\log e_{t}=\log A+0,3296 \cdot \log e_{t-1}+0,5299 \cdot \log e_{t-2}-0,0548 \cdot \log p_{t-1},
$$

donde $p$ es el precio de la energía y $A$ incluye a los restantes factores que afectan a la demanda, los que se suponen constantes. Si el mes 0 el precio aumenta desde $p$ a $p+\Delta p$, entonces al mes siguiente la cantidad demandada será

$$
\log e_{1}=\log A+0,3296 \cdot \log e_{0}+0,5299 \cdot \log e_{-1}-0,0548 \cdot \log (p+\Delta p) .
$$

Si este cambio se mantiene, al cabo de dos meses el consumo será

$$
\log e_{2}=\log A+0,3296 \cdot \log e_{1}+0,5299 \cdot \log e_{0}-0,0548 \cdot \log (p+\Delta p)
$$

y así sucesivamente. Si además suponemos que antes del cambio $e_{0}=\mathrm{e}_{-1}=$ 100 , se sigue que

$$
\Delta e(1, p+\Delta p)=100-e_{1}
$$

es la caída porcentual del consumo durante el primer mes; de manera similar,

$$
\Delta e(2, p+\Delta p)=100-\frac{e_{1}+e_{2}}{2}
$$


es la caída porcentual total del consumo durante el primero y el segundo mes si el precio durante $t=0 \mathrm{y} t=1$ se mantiene en $p+\Delta p$; y en $n$ meses, la caída total del consumo es

$$
\Delta e(n, p+\Delta p)=100-\frac{1}{n} \sum_{i=1}^{n} e_{i}
$$

Cada celda en el Cuadro $\mathrm{N}^{\circ} 4$ computa $\Delta e(n, p+\Delta p)$ para $n$ y $\Delta p$ alternativos. El panel $a$ toma como precio base US\$ 0,09/KWh. La columna 1 , entonces, muestra la caída del consumo si el precio aumenta a US\$ $0,1 /$ KWh en un mes, dos meses y hasta 10 meses.

El costo total estimado de una restricción es a lo más

$$
\left(n \cdot 100-\sum_{i=1}^{n} e_{i}\right) \times(p+\Delta p) .
$$

Éste se compara con el costo actual de una restricción:

$$
\left(n \cdot 100-\sum_{i=1}^{n} e_{i}\right) \times 21,2 .
$$

\section{Tarificación de distribución y la tarifa BT1}

Las distribuidoras son empresas de servicio público cuyos deberes y derechos fueron establecidos por el DFL N ${ }^{\circ} 1$ de 1982 (Ministerio de Minería, 1982). Entre sus deberes, se encuentran el dar suministro en su zona de concesión, entregar un nivel mínimo de calidad, mantener y operar instalaciones seguras, interconectarse con otros concesionarios y permitir el uso de líneas eléctricas para transporte de energía de cualquier generador. Para cumplir con sus obligaciones pueden solicitar concesión de servicio público, usar bienes nacionales de uso público y las servidumbres otorgadas por concesión y recibir tarifas reguladas que les aseguran la rentabilidad a las empresas eficientes de referencia. En este apéndice describimos brevemente el negocio de la distribución y examinamos las principales fórmulas tarifarias. 


\section{D.1. Las redes de distribución}

La red de distribución es el medio a través del cual se transmite energía y potencia desde los bordes del sistema troncal de transmisión en alta tensión hasta el cliente final. Los elementos más importantes que componen una red son las líneas de transmisión, aéreas o subterráneas, cuyas dimensiones están determinadas por las magnitudes de los voltajes y las potencias a transportar, los transformadores, los conectores y desconectores, los empalmes y los equipos de medición y control.

Las redes se pueden caracterizar de acuerdo con su nivel de tensión: alta, media y baja, aunque en Chile sólo se usa la terminología de alta y baja tensión. Los distintos niveles de tensión se justifican por la diversidad de los tamaños de los consumos y por la necesidad de reducir las pérdidas térmicas en líneas y equipos, las que son menores a mayores niveles de tensión.

Según la legislación chilena, son clientes en alta tensión aquellos que están conectados con su empalme a líneas de voltaje superior a 400 volts. Son clientes en baja tensión aquellos que están conectados con su empalme a líneas de voltaje igual o menor que 400 volts.

\section{D.2. Tarifas: conceptos básicos}

Según Rudnick y Raineri (1997), el mecanismo de regulación existente en Chile, corresponde a un modelo de tarificación por incentivos, tipo yardstick competition (competencia por comparación), donde se evalúa el comportamiento relativo de la industria, asegurándose una cierta rentabilidad a las empresas con un comportamiento similar al de una empresa modelo. Esta empresa modelo se deriva de una empresa real tal que todos sus procesos y redes físicas se encuentran optimizados. La ley establece un esquema de precios regulados de la cadena generación-transmisión-distribución, para clientes con un consumo menor que $500 \mathrm{KW}$ (la Ley $\mathrm{N}^{\circ} 19.940$ de 2004 redujo el límite desde $2.000 \mathrm{KW}$ hasta $500 \mathrm{KW}$ ).

El precio final que paga un consumidor regulado se compone del precio de nudo de la energía y de la potencia, al cual las distribuidoras le compran a los generadores; el costo de transporte y un cobro por el servicio de distribución. Adicionalmente, el regulador ha introducido un valor agregado por el servicio de subtransmisión que es el puente entre la generación-transporte y las redes de distribución, y que es calculado por el regulador junto con las tarifas de distribución. 
D.2.1. Precio regulado de la energía y de la potencia: el precio de nudo

El precio regulado a nivel generación se denomina precio de nudo y tiene sus componentes de energía y potencia. El precio de la energía corresponde a un promedio de los costos marginales de corto plazo esperados para los próximos cuatro años. Por su parte, el precio de la potencia equivale al costo de expansión del sistema, representado como el costo de instalar unidades que puedan abastecer la demanda de la punta.

En las tarifas finales, a ambos se les agregan recargos por transporte en alta tensión y factores de penalización que representan el costo marginal de transportar la energía y potencia desde la subestación básica hasta los nudos de retiro en alta tensión de las empresas distribuidoras. Adicionalmente la ley 19.940 de 2004 introdujo un cargo estampillado por el uso de la red troncal de transporte para cubrir la totalidad de su costo. Estos precios y recargos los calcula semestralmente la Comisión Nacional de Energía (CNE).

\section{D.2.2. Precio regulado del servicio de distribución: el VAD}

El precio regulado del servicio de distribución es el valor agregado medio por esta actividad, determinado a partir de empresas modelo que operan en el país, y que se establece en base al valor agregado de distribución (VAD). El VAD se basa en una empresa modelo y sus principales componentes son:

- Los costos fijos por gastos de administración, facturación y atención del cliente final.

- Los costos estándares de inversión, mantención y operación de la red de distribución y que se expresan por unidad de potencia suministrada. Los costos anuales de inversión se calculan considerando el valor nuevo de reemplazo (VNR) de las instalaciones adaptadas a la demanda, su vida útil y una tasa de actualización del $10 \%$ real anual.

- Las pérdidas medias de potencia y energía. Dentro de las redes de distribución se producen pérdidas de energía y potencia. Estas pérdidas pueden ser de naturaleza técnica, debido a pérdidas físicas en las redes, o bien de naturaleza no técnica, debido a robos.

Los componentes indicados se calculan para diferentes áreas de distribución típicas, establecidas por CNE. El objetivo de la fijación de los VNR es calcular el costo de renovar todas las obras, instalaciones y bienes 
físicos necesarios para dar el servicio de distribución, en las respectivas concesiones. Según Rudnick y Raineri (1997), el VNR usado en la legislación chilena corresponde a un híbrido entre el costo de sustitución y el costo de reposición de los equipos y líneas de la red.

Adicionalmente, cabe señalar que los costos adicionales en que incurre la empresa distribuidora por las pérdidas de energía y potencia dentro de sus redes se reconoce mediante los así llamados factores de expansión de pérdidas que ponderan el precio de la energía y la potencia de punta.

\section{D.3. Determinación de los cargos incorporados en las tarifas finales de las distribuidoras}

Hay varias tarifas reguladas de distribución. Sin embargo, cada una de ellas se puede separar de la siguiente manera:

Tarifa $=($ cargo por la energía consumida $)+($ cargo por la potencia demandada durante horas de punta) + (cargo fijo) + (cargo por uso de la red de distribución).

En realidad, los cobros por energía y potencia no son cargos de distribución propiamente tales, sino de comercialización. De hecho, la regulación supone que los distribuidores simplemente les traspasan estos cargos a los consumidores, sin ganar un margen sobre ellos. Todos los servicios ofrecidos por el distribuidor son remunerados ya sea por el cargo fijo (que corresponde, principalmente, al costo del medidor, la medición y la facturación) o por el cargo por uso de las redes de distribución. Nuestra propuesta de separar los cargos de distribución de los de comercialización consiste precisamente en separar el cargo fijo y el cargo por uso de la red de distribución de las tarifas de energía y potencia. A continuación examinamos cada cargo por separado.

El cargo por consumo de energía. El cargo por energía paga el costo de suministrarle energía al cliente final en su punto de conexión a la red. Este cargo es igual al consumo de energía del cliente (e), multiplicado por el precio de nudo de energía en la barra en que es suministrada la empresa distribuidora $\left(p_{N}^{e}\right)$ y por un factor que da cuenta de la energía que se pierde entre la barra en que fue calculado el precio de nudo y el punto de suministro al cliente $\left(1+\lambda_{e}\right)$. De este modo el cargo por el consumo de energía se puede escribir como

$$
\text { cargo por energía }=e \cdot p_{N}^{e} \cdot\left(1+\lambda_{e}\right) .
$$


D.3.1. El cargo por consumo de potencia durante las horas punta del sistema

En teoría, al cliente se le debería cobrar la potencia que consume en la hora punta del sistema ( $\mathrm{PP}^{*}$ en el Gráfico $\mathrm{N}^{\circ} \mathrm{A} 1, \pi^{\text {punta }}$ en la ecuación que sigue), aun si su demanda máxima de potencia es mayor. El principio es que la potencia en horas fuera de la punta es redundante y por ende no tiene costo de oportunidad. Al cliente se le debería cobrar el precio de nudo de la potencia $\left(\mathrm{p}_{N}^{\pi}\right)$ ajustado por las pérdidas entre la barra en que fue calculado el precio de nudo y el punto de suministro al cliente $\left(1+\lambda_{e}\right)$. El cargo por potencia sería entonces

$$
\text { cargo por potencia }=\pi^{\text {punta sistema }} \cdot \mathrm{p}_{N}^{\pi} \cdot\left(1+\lambda_{\pi}\right)
$$

En la práctica, se define como período de punta a las cinco horas entre las 6 de la tarde y las 11 de la noche entre mayo y septiembre, cuando ocurre la cantidad de demanda máxima. Por eso podría ser el caso que el cliente pague más potencia de la que usa a la hora punta del sistema. Esta situación se muestra en el Gráfico $\mathrm{N}^{\circ} \mathrm{A} 1$, donde el consumo máximo del cliente durante el "período de punta", PP, es mayor que su consumo durante la punta del sistema, $\mathrm{PP}^{*}$ ).

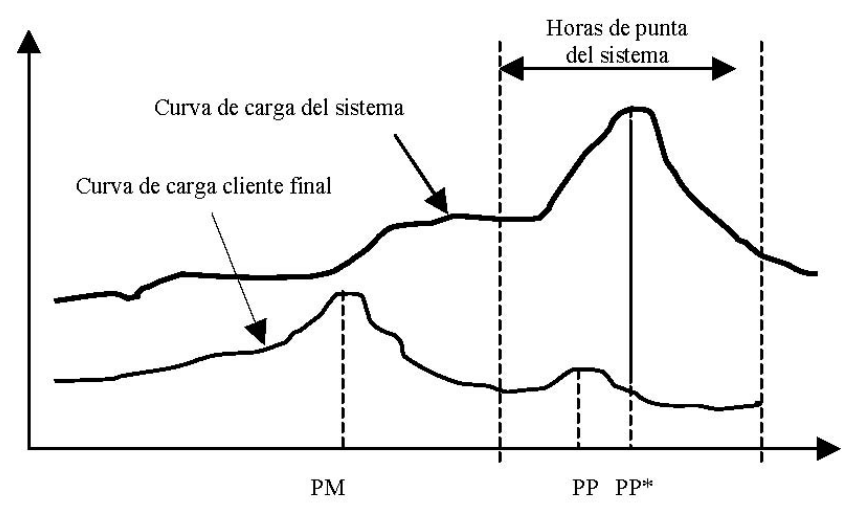


Cargo por el uso de la red de distribución. Según se señaló, el cargo por el uso de la red de distribución trata de cuantificar el "uso" que el cliente hace de la red de distribución. Según esto, por ejemplo, un cliente que esté conectado a la red de distribución en alta tensión sólo deberá pagar por las instalaciones de alta tensión. De forma similar un cliente que esté conectado a la red de distribución en el nivel de baja tensión deberá pagar por las instalaciones de alta y baja tensión y en proporción al uso que hace de ellas.

El uso que hace un cliente de las instalaciones de distribución se mide como su demanda durante la hora de mayor tránsito en la red a la que está conectado, $\mathrm{PM}^{*}$ en el Gráfico $\mathrm{N}^{\circ} \mathrm{A} 2$. La idea, nuevamente, es que las instalaciones de distribución deben dimensionarse para el consumo máximo. Nótese que el consumo máximo de determinada instalación de distribución no coincide necesariamente con la punta de todo el sistema eléctrico, posibilidad que se representa en el Gráfico $\mathrm{N}^{\circ} \mathrm{A} 2$.

Si $\pi^{\text {punta red }}$ es la demanda del cliente durante la hora de mayor tránsito en la red, y VAD el precio unitario de un KW de capacidad de la red de distribución, el cargo se puede escribir como

$$
\text { cargo por distribución }=\pi^{\text {punta red }} \cdot \operatorname{VAD} \cdot\left(1+\lambda_{\pi}\right) \text {. }
$$

GRÁFICO $N^{\circ}$ A2: CURVA DE DEMANDA POR CAPACIDAD EN LOS TRAMOS RELEVANTES DE LA RED DE DISTRIBUCIÓN

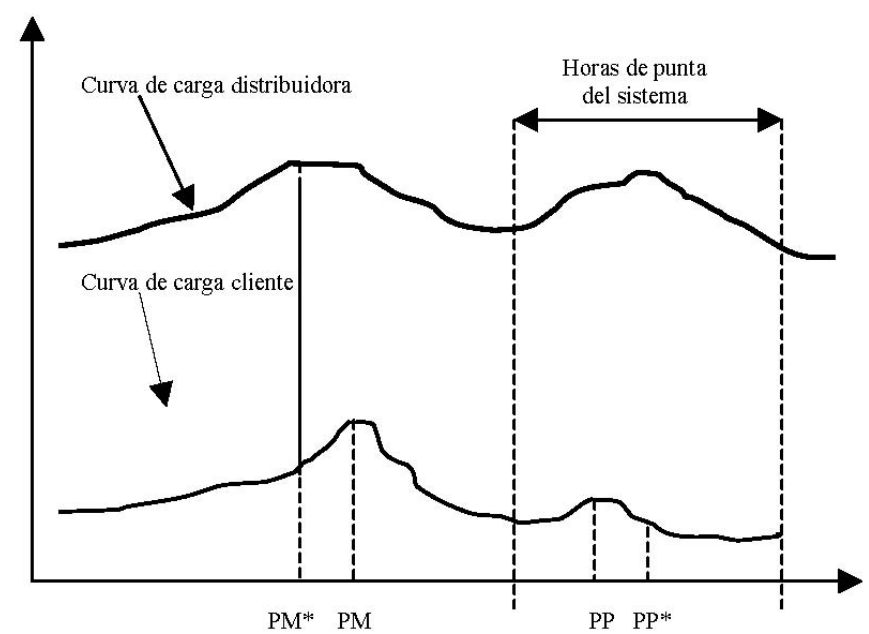


Nótese que el factor de pérdidas es el mismo que en la ecuación (D.1). Esto es así porque por las pérdidas las instalaciones deben dimensionarse para distribuir más de lo que el cliente retira.

\section{D.4. Tarifas}

En principio, un cliente puede elegir libremente cualquiera de las tarifas fijadas en los decretos tarifarios con las limitaciones y condiciones de aplicación establecidas en cada caso y dentro del nivel de tensión que les corresponda. Sin embargo, el acceso a las distintas tarifas depende del tipo de medidor que tenga el cliente. $\mathrm{Si}$ a cada cliente se le midiera su consumo máximo de potencia en las horas de punta del sistema, su consumo máximo y su consumo de energía, bastaría con definir un solo esquema tarifario basado en cargos que se apliquen a cada una de las variables medidas. Sin embargo, cuando se diseñó la regulación vigente (el DFL $\mathrm{N}^{\circ} 1$ de 1982) los medidores que permiten registrar el consumo horario de potencia eran muy caros, y se definieron tarifas que permitían estimar, a través de factores de responsabilidad o de coincidencia de la carga, el consumo de potencia en horas de punta y el consumo máximo del cliente. Esto dio origen a tres clases de tarifas.

Tarifas horarias. Para aplicar este tipo de tarifa se mide el consumo de potencia del cliente en cada momento, dentro o fuera de las horas de punta del sistema, y la energía que consume durante todo el período de medición. Esta tarifa es para clientes conectados en alta tensión, en general grandes clientes industriales.

Tarifas de demanda máxima. Para aplicar este tipo de tarifa se mide el consumo máximo de potencia (sin distinguir si éste ocurre dentro o fuera de las horas de punta) y de energía. Esta opción se da tanto en alta tensión como en baja tensión y es aplicable a clientes industriales y comerciales medianos o pequeños.

Tarifa simple. Para aplicar esta tarifa se mide solamente el consumo de energía. Es aplicable para clientes residenciales y comerciales pequeños y corresponde a la tarifa BT1.

Puesto que en este trabajo nos interesa la tarifa BT1, a continuación la describimos con más detalle. La tarifa BT1 es aplicable a los clientes en 
baja tensión y con medidor sólo de energía. Tal como se indicó anteriormente, para calcularla se estima el consumo de potencia en la hora punta a partir del consumo de energía. Ello se hace mediante el factor de carga promedio del grupo agregado de los clientes respectivos: esto es la razón entre la demanda promedio de potencia y la demanda máxima.

El factor de responsabilidad en horas de punta del sistema se estima a partir de la energía consumida y de un factor medio de carga constante, expresado como horas de utilización de la potencia de punta efectiva, y es igual a

(factor de carga promedio) $\cdot 8.760$.

Por lo tanto, la cuenta de un cliente con este tipo de tarifa es:

$$
\text { cargo fijo }+e \cdot p_{N}^{e} \cdot\left(1+\lambda_{e}\right)+e \cdot \frac{\left(p_{N}^{\pi}+\mathrm{VAD}\right) \cdot\left(1+\lambda_{\pi}\right)}{(\text { factor de carga promedio }) \cdot 8.760} .
$$

La tarifa BT1 es, entonces:

$$
p_{N}^{e} \cdot\left(1+\lambda_{e}\right)+\frac{\left(p_{N}^{\pi}+\mathrm{VAD}\right) \cdot\left(1+\lambda_{\pi}\right)}{(\text { factor de carga promedio }) \cdot 8.760} .
$$

Nuestra propuesta consiste en separar el cargo de distribución de los cargos por comercialización de energía y potencia. Así, habría tres tarifas:

a) es la tarifa de energía:

$$
p_{N}^{e} \cdot\left(1+\lambda_{e}\right)
$$

b) es la tarifa de potencia:

$$
p_{N}^{\pi} \cdot\left(1+\lambda_{\pi}\right)
$$

c) es el cargo por distribución:

$$
\text { cargo fijo }+\mathrm{VAD} \cdot\left(1+\lambda_{\pi}\right) \cdot \pi^{\text {punta red }}
$$




\section{REFERENCIAS}

Arellano, S.: "Market Power in Mixed Hydro-Thermal Electric Systems", Documento de Trabajo N 187, Centro de Economía Aplicada, Universidad de Chile, 2004.

Benavente, J., A. Galetovic, R. Sanhueza y P. Serra: "Estimando la Demanda Residencial por Electricidad en Chile: La Demanda es Sensible al Precio". Mimeo, 2004. Aceptado en Cuadernos de Economía.

Bernstein, S.: "Regulación en el Sector de Distribución Eléctrica". Tesis de Ingeniero Civil Industrial. Santiago: Pontificia Universidad Católica, 2000.

Bustos, A. y A. Galetovic: "Regulación por Empresa Eficiente: ¿Quién es Realmente Usted?". Estudios Públicos, 86, 2002.

Chumacero, R., R. Fuentes y K. Schmidt-Hebbel: "Chile's Free Trade Agreements: How Big is the Deal?" Serie Investigación N ${ }^{\circ}$ 264, Banco Central de Chile, 2004.

Díaz, C., A. Galetovic y R. Soto: "La Crisis Eléctrica de 1998-1999: Causas, Consecuencias y Lecciones”. Estudios Públicos 80, 2000.

Díaz, C., A. Galetovic y R. Soto: "Anatomía de una Crisis Eléctrica”. Revista de Análisis Económico, 16, 2001.

Fierro, G. y P. Serra: “Outage Costs in Chilean Industry”. Energy Economics, 19, 1997.

Fischer, R. y A. Galetovic: "Regulatory Governance and Chile's 1998-1999 Electricity Shortage”. Journal of Policy Reform 6, 2003.

Galetovic, A.: "Integración Vertical en el Sector Eléctrico: Una Guía para el Usuario". Estudios Públicos, 91, 2003.

Galetovic, A., J. C. Olmedo y H. Soto: "Una Estimación del Costo Social de Eliminar los Déficit de Abastecimiento Eléctrico en el SIC”. Revista de Análisis Económico, 17, 2002.

Ministerio de Economía, Fomento y Reconstrucción: Ley N 19.940, 2004.

Ministerio de Economía Fomento y Reconstrucción: Decreto $\mathrm{N}^{\circ} 632$ que fija fórmulas tarifarias para las empresas eléctricas concesionarias de servicio público de distribución, 2000.

Ministerio de Minería: Decreto con Fuerza de Ley Nº 1, 1982.

Molina, P.: "Tarificación Eléctrica Chilena a Nivel de Empresas de Distribución". Tesis de Magíster en Ciencias de la Ingeniería. Santiago: Pontificia Universidad Católica de Chile, 1998.

Montero, J. P. y H. Rudnick: "Precios Eléctricos Flexibles". Cuadernos de Economía 38, 2001.

Rudnick, H. y R. Raineri: “Chilean Distribution Tariffs: Incentive Regulation”. En F. Morandé y R. Raineri (eds.), (De)regulation and Competition: The Electric Industry in Chile. Santiago: Ilades/Georgetown University, 1997.

Serra, P.: "Energy Pricing Under Uncertain Supply". Energy Economics, 19, 1997.

Synex Consultores: "Consultoría Especializada para la Evaluación de Procedimientos en la Fijación de Tarifas al Consumidor Final y Peajes Aplicables al Sector Eléctrico en la República del Ecuador". 1999.

Valdés, S.: "Para Aumentar la Competencia entre las AFP". Mimeo, 2004. 
Valdés, S. e I. Marinovic: “Contabilidad Regulatoria: Las AFP Chilenas 1993-2003”. Mimeo, 2004.

Taulis, E.: De la Distribution des Pluies au Chili: Le Périodicité des Pluies depuis Quatre Cents Ans". Materiaux Pour L'Etude de Calamites, 33, 1934. 